RESEARCH

SERIES

NUMBER 80

April 2019

\title{
REFORMING THE DELIVERY OF PUBLIC DENTAL SERVICES IN IRELAND POTENTIAL COST IMPLICATIONS
}

\author{
ANNE NOLAN
}

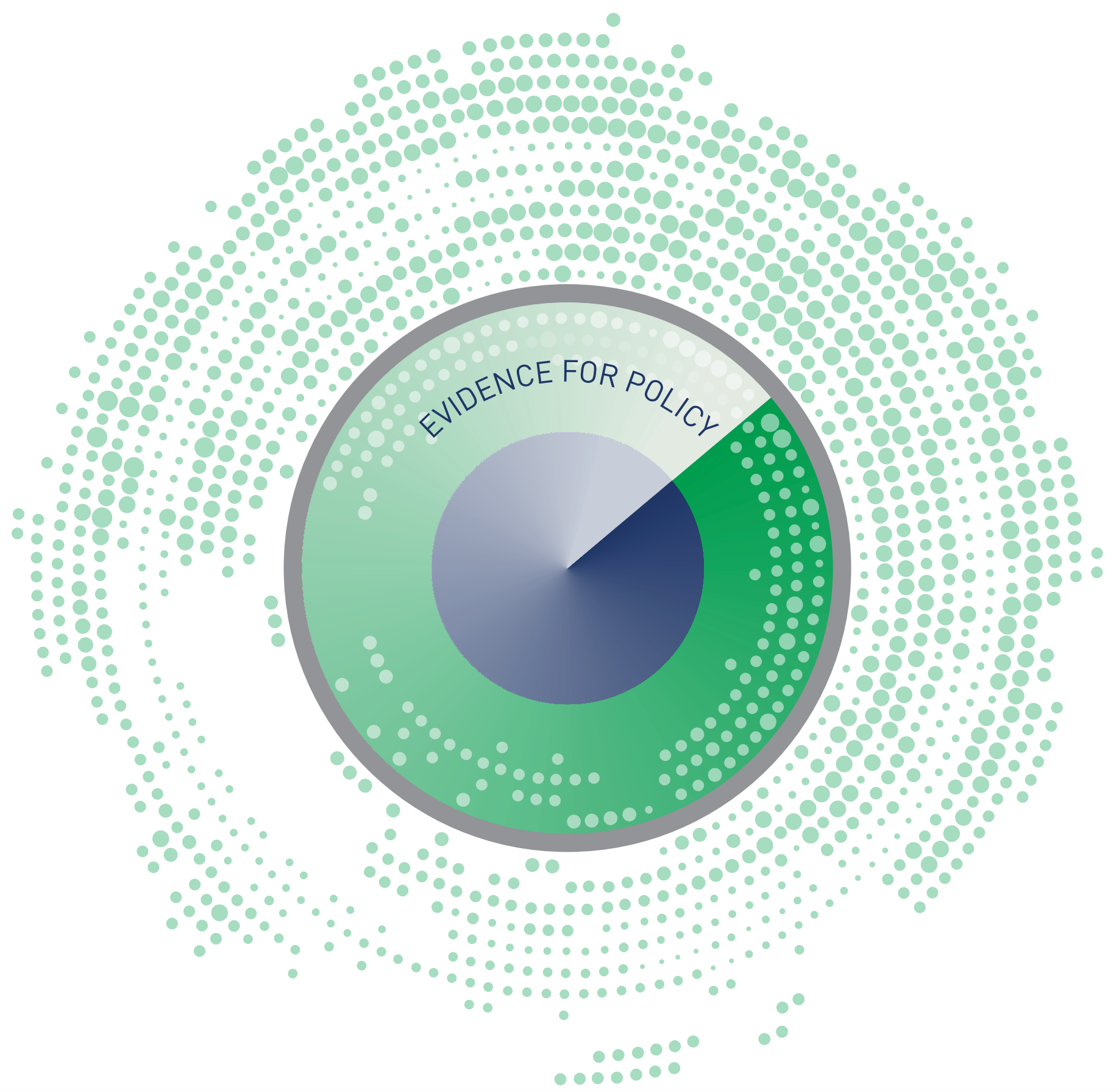




\section{REFORMING THE DELIVERY OF PUBLIC DENTAL SERVICES IN IRELAND: POTENTIAL COST IMPLICATIONS}

Anne Nolan

April 2019

\section{RESEARCH SERIES}

\section{NUMBER 80}

Available to download from www.esri.ie

(C) The Economic and Social Research Institute

Whitaker Square, Sir John Rogerson's Quay, Dublin 2

ISBN 978-0-7070-0471-6

DOI https://doi.org/10.26504/rs80

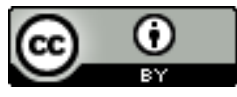

This Open Access work is licensed under a Creative Commons Attribution 4.0 International License (https://creativecommons.org/licenses/by/4.0/), which permits unrestricted use, distribution, and reproduction in any medium, provided the original work is properly credited. 



\section{ABOUT THE ESRI}

The mission of the Economic and Social Research Institute is to advance evidencebased policymaking that supports economic sustainability and social progress in Ireland. ESRI researchers apply the highest standards of academic excellence to challenges facing policymakers, focusing on 12 areas of critical importance to $21^{\text {st }}$ Century Ireland.

The Institute was founded in 1960 by a group of senior civil servants led by Dr T.K. Whitaker, who identified the need for independent and in-depth research analysis to provide a robust evidence base for policymaking in Ireland.

Since then, the Institute has remained committed to independent research and its work is free of any expressed ideology or political position. The Institute publishes all research reaching the appropriate academic standard, irrespective of its findings or who funds the research.

The quality of its research output is guaranteed by a rigorous peer review process. ESRI researchers are experts in their fields and are committed to producing work that meets the highest academic standards and practices.

The work of the Institute is disseminated widely in books, journal articles and reports. ESRI publications are available to download, free of charge, from its website. Additionally, ESRI staff communicate research findings at regular conferences and seminars.

The ESRI is a company limited by guarantee, answerable to its members and governed by a Council, comprising 14 members who represent a cross-section of ESRI members from academia, civil services, state agencies, businesses and civil society. The Institute receives an annual grant-in-aid from the Department of Public Expenditure and Reform to support the scientific and public interest elements of the Institute's activities; the grant accounted for an average of 30 per cent of the Institute's income over the lifetime of the last Research Strategy. The remaining funding comes from research programmes supported by government departments and agencies, public bodies and competitive research programmes.

Further information is available at www.esri.ie 


\section{THE AUTHORS}

Anne Nolan is an Associate Research Professor at the ESRI, and Adjunct Professor at Trinity College Dublin.

\section{ACKNOWLEDGEMENTS}

This research was carried out as part of the joint ESRI/Department of Health Research Programme on Healthcare Reform. I would like to thank the members of the Research Programme Steering Group for their guidance on the research, and in particular Teresa Maguire (Department of Health) for her advice throughout the project. Thanks also to Dympna Kavanagh and Bernadette McDonnell (Department of Health) for providing additional data and documentation and for helpful comments on earlier drafts of the report. The final report also benefited greatly from the reviews received from two international experts and two ESRI research staff members.

This report has been accepted for publication by the Institute, which does not itself take institutional policy positions. All ESRI Research Series reports are peer reviewed prior to publication. The author is solely responsible for the content and the views expressed. 


\section{Table of Contents}

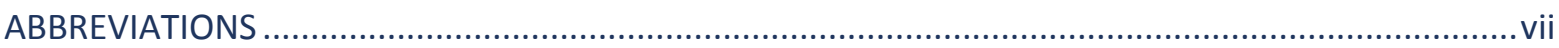

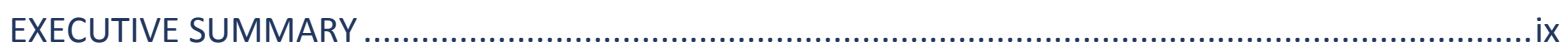

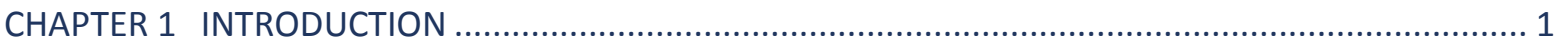

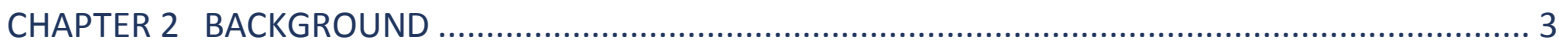

2.1 Irish healthcare system ...................................................................... 3

2.2 Financing and delivery of dental healthcare services..................................... 3

2.3 Development of the National Oral Health Policy ............................................. 5

CHAPTER 3 PROVIDER PAYMENT METHODS - LITERATURE REVIEW ...................................... 7

3.1 Introduction .................................................................................... 7

3.2 Methods of provider payment in primary care and dentistry............................ 7

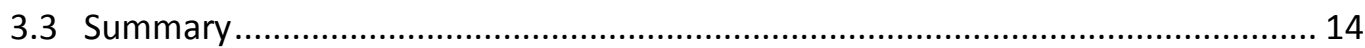

CHAPTER 4 COSTING DENTAL HEALTHCARE SERVICES (ADULT MEDICAL CARDHOLDERS) ............. 17

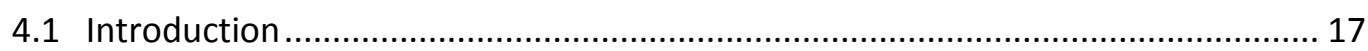

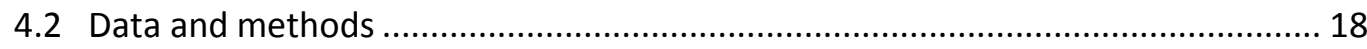

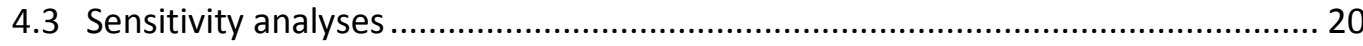

4.4 Results........................................................................................ 21

CHAPTER 5 COSTING DENTAL HEALTHCARE SERVICES (CHILDREN) ....................................... 25

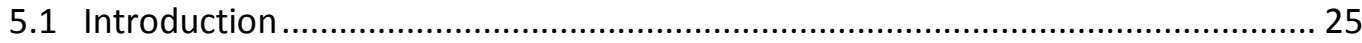

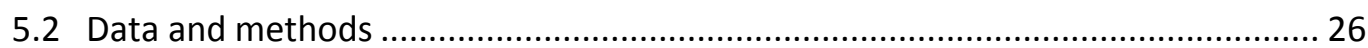

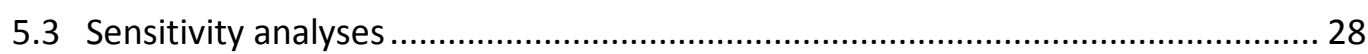

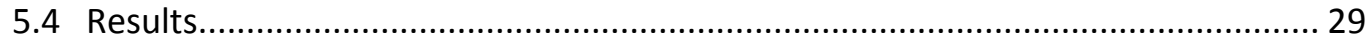

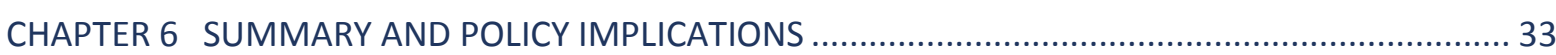

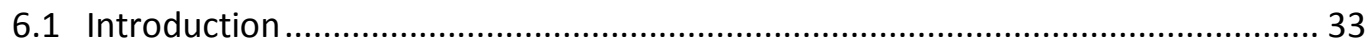

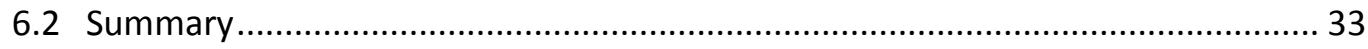

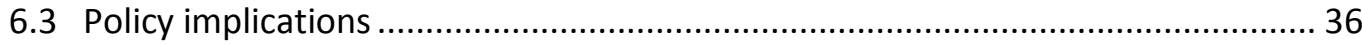




\section{List of Tables}

Table 4.1 Proposed dental healthcare services for adult medical cardholders

Table 4.2 Existing treatments and schedule of fees under the DTSS (adult medical cardholders)

Table 4.3 Treatment prices, eligible population, take-up and usage frequency for baseline scenario (adult medical cardholders)

Table 4.4 Baseline scenario (adult medical cardholders)

Table 4.5 Alternative scenarios (adult medical cardholders)

Table 4.6 Approximate package payment by age group (baseline scenario, adult medical cardholders)

Table 5.1 Existing treatments for children under the public dental service (PDS) ....................... 25

Table 5.2 Proposed dental healthcare services for children..................................................... 25

Table 5.3 Treatment prices, eligible population, take-up and usage frequency for baseline scenario (children)

Table 5.4 Baseline scenario (children) 30

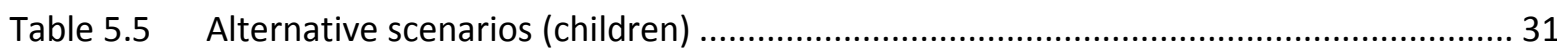

Table 5.6 Approximate package payment by age group (baseline scenario, children) 32 


\section{Abbreviations}

$\begin{array}{ll}\text { ATL } & \text { Above-the-line treatment } \\ \text { BTL } & \text { Below-the-line treatment } \\ \text { CSO } & \text { Central Statistics Office } \\ \text { DMFT } & \text { Decayed, missing or filled tooth } \\ \text { DRG } & \text { Diagnosis-related group } \\ \text { DTSS } & \text { Dental Treatment Services Scheme } \\ \text { EU } & \text { European Union } \\ \text { GP } & \text { General practitioner } \\ \text { GUI } & \text { Growing Up in Ireland survey } \\ \text { HSE } & \text { Heath Service Executive } \\ \text { FACCT } & \text { Fluoride and Caring for Children's Teeth study } \\ \text { FFS } & \text { Fee-for-service } \\ \text { NHS } & \text { National Health Service } \\ \text { OECD } & \text { Organisation for Economic Cooperation and Development } \\ \text { PCRS } & \text { Primary Care Reimbursement Service } \\ \text { PDS } & \text { Public Dental Service } \\ \text { P4P } & \text { Pay for performance } \\ \text { PHI } & \text { Private health insurance } \\ \text { PRSI } & \text { Pay related social insurance } \\ \text { RCT } & \text { Randomised control trial } \\ \text { TBS } & \text { Treatment Benefit Scheme } \\ \text { TILDA } & \text { The Irish Longitudinal Study on Ageing } \\ \text { UK } & \text { United States } \\ \text { US } & \end{array}$





\section{EXECUTIVE SUMMARY}

This report details the results of an analysis of the potential cost implications of proposed changes to aspects of the model of delivery of publicly-financed dental services in Ireland, as set out in the new National Oral Health Policy (Department of Health, 2018b). Currently, dental services in Ireland are financed and delivered in a mixed public-private system, with most individuals paying out-of-pocket fees to independent dental practitioners. The public system currently finances the delivery of dental healthcare services to adult medical cardholders via the Dental Treatment Services Scheme (DTSS); to non-medical cardholder eligible adults via the Treatment Benefit Scheme (TBS); and to children and adults requiring special and complex care via the Public Dental Service (PDS). This report deals with proposed changes to the delivery of preventive dental healthcare services under the DTSS and PDS.

One of the key provisions of the new National Oral Health Policy is to provide packages of preventive dental healthcare services for two key population groups (i.e. eligible adults with Medical Cards, and children). For both adult medical cardholders and children, the scope of publicly-financed services available will change, while the delivery setting will also change for children, from the public dental service to independent practice. Dentists in independent practice will also face a change in reimbursement method, from fee-for-service to prospective payment for specified packages of preventive dental healthcare services. This report reviews the literature on methods of provider payment for primary care and dental services, and assesses the implications for public expenditure of proposed changes to the delivery of services to these two population groups.

The review of the theoretical and empirical literature on provider payment methods in primary care and dentistry highlights that the optimal mix between the main methods of provider payment - namely capitation, fee-for-service and salary - is still undecided. The choice of payment method in part depends on the importance of different policy priorities such as access, efficiency and quality. New payment initiatives such as pay for performance (P4P) are being implemented in many countries, but their success is dependent on the accuracy with which outcomes can be measured. Many countries are now experimenting with bundled payment initiatives, mainly in acute care settings, although these initiatives have not yet been subject to rigorous evaluations of their impacts on efficiency, access, quality and patient health outcomes.

While it is difficult to predict how dentists will respond to the changes in reimbursement proposed under the National Oral Health Policy, to the extent that 
the mix of services reimbursable in the public system will now change, this may be expected to result in differences in the mix of services provided by dentists. In addition, for the provision of services to adult medical cardholders, the movement from fee-for-service to prospective payment will change provider incentives, although the full impact of the change is difficult to predict without also considering how patients will react. In any case, under the National Oral Health Policy, dentists will (continue to) face different payment methods for different services and different population groups, and the full implications of these different payment methods and resulting incentives will need to be monitored carefully in the implementation of the new policy.

The assessment of the expenditure implications of alternative preventive dental healthcare packages results in a range of annual expenditure figures for both adult medical cardholders and children. The annual cost of a package of care under the baseline scenario for adult medical cardholders is estimated to be $€ 23.0$ million, with estimates under alternative scenarios ranging from $€ 6.9$ million to $€ 42.8$ million. Annual expenditure for the provision of a primary dental care service to all children under the age of 16 years is estimated to be $€ 26.5$ million, with estimates under alternative scenarios ranging from $€ 26.0$ million to $€ 41.1$ million. The range of estimates reflects differing assumptions about the scope of services available (e.g. allowance for extractions), eligible population (e.g. relevant population for fluoride therapy) and usage frequency (e.g. annual vs. biennial oral examinations), and illustrates the sensitivity of cost estimates to differences in key policy parameters.

This range of estimates is designed to assist policymakers tasked with designing an alternative package of preventive dental healthcare services, and associated provider payment structure, for adult medical cardholders and children respectively. Further analysis of the capacity (i.e. staff, equipment, etc.) implications, potential behaviour change on the part of both providers and patients, as well as estimates of the cost of additional packages of services to cover more complex interventions such as crowns, endodontic treatment, etc. will be required in order to assess the full implications of the proposed policy changes for public dental expenditure, practice and outcomes in Ireland. 


\section{CHAPTER 1}

\section{Introduction}

This report details the results of an analysis of the potential cost implications of proposed changes to aspects of the model of delivery of publicly-financed dental services in Ireland, as set out in the new National Oral Health Policy (Department of Health, 2018b). This research was carried out as part of a programme of research at the Economic and Social Research Institute (ESRI) funded by the Department of Health. The ESRI Research Programme on Healthcare Reform was agreed between the ESRI and the Department of Health in July 2014. The objectives of the programme are to apply economic analysis to explore issues in relation to health services, health expenditure and population health, in order to inform the development of health policy. The programme is overseen by a Steering Group comprising nominees of the ESRI and the Department of Health, which agrees its annual work programme. ${ }^{1}$

Currently, dental services in Ireland are financed and delivered in a mixed publicprivate system. Services are financed largely by out-of-pocket payments by individuals to dental practitioners operating in independent practice. The Central Statistics Office (CSO) estimates that a total of $€ 603$ million was paid to dental practitioners for dental services in 2015, of which 83 per cent was accounted for by direct out-of-pocket payments by individuals (CSO, 2017). The public system currently finances the delivery of dental healthcare services to adult medical cardholders via the Dental Treatment Services Scheme (DTSS), to non-medical cardholder eligible adults via the Treatment Benefit Scheme (TBS), and to children and adults requiring special and complex care via the Public Dental Service (PDS).

The National Oral Health Policy replaces the existing Dental Health Action Plan, which dates back to 1994 (Department of Health, 1994). One of the key provisions of the new policy is to establish a re-orientated public service for two key population groups (i.e. eligible adults with Medical Cards, and children) (Department of Health, 2018b). In this report, we assess the implications for public expenditure of these proposed changes to the delivery of services to these two population groups. A range of scenarios is examined for each population group, highlighting the potential trade-offs involved in the design of alternative packages of dental healthcare services. As the proposed changes to the delivery models involve changing the method of remunerating dentists for services 
provided to these two population groups, the report also contains a review of the literature on methods of provider payment for dental services.

This report is structured as follows. Section 2 provides a brief description of the Irish healthcare system, describes current policy with regard to dental healthcare in Ireland, and outlines the current financing and delivery of dental healthcare services for both adults and children. Section 3 reviews the literature on methods for reimbursing dentists for the provision of dental healthcare services, with a particular focus on emerging methods of provider payment such as bundled methods of payment. Sections 4 and 5 then assess the public expenditure implications of the proposed changes to the delivery of dental healthcare services to adult medical cardholders and children respectively. Section 6 discusses the findings from the analysis and further implications for policy. 


\section{CHAPTER 2}

\section{Background}

\subsection{IRISH HEALTHCARE SYSTEM}

In 2015 , Ireland spent $€ 3,939$ per capita on healthcare (9.7 per cent of gross national income), compared to the EU average of $€ 2,797 .{ }^{2}$ Approximately 70 per cent of this spending is publicly-funded, with the remainder largely funded from out-of-pocket payments (15 per cent) and voluntary health insurance payments (12 per cent) (OECD, 2018). Healthcare services are delivered in both the public and private sectors, and many publicly-funded health services are delivered by self-employed providers (e.g. general practitioners, dentists, etc.).

Currently, there are two main categories of entitlements to public health services. Those in Category I (medical cardholders) are entitled to free public health services (including inpatient and outpatient hospital care, general practitioner (GP) care and other primary and community care services). ${ }^{3}$ Those in Category II are entitled to subsidised public hospital services and prescription medicines, but must pay the full cost of primary and community care services. There are additional public services available for children (e.g. childhood immunisations, some dental, ophthalmic and aural services), and additional entitlements for individuals in special circumstances. ${ }^{4}$ Eligibility for a Medical Card is assessed primarily on the basis of an income means test, and approximately 35 per cent of the population has a Medical Card (Department of Health, 2018a). Currently approximately 45 per cent of the population have private health insurance (PHI), which mainly provides coverage for private or semi-private acute hospital services, but which increasingly offers partial reimbursement of certain primary care expenses (e.g. GP visits, routine dental care, physiotherapy, etc.) (Health Insurance Authority, 2018).

\subsection{FINANCING AND DELIVERY OF DENTAL HEALTHCARE SERVICES}

Prior to the publication of the National Oral Health Policy, policy on the provision of dental services in Ireland was based on the 1994 Dental Health Action Plan (Department of Health, 1994). One of the major components of the plan was the provision for the establishment of the Dental Treatment Services Scheme (DTSS).

Caution is advised in making international comparisons using these data. In particular, there are differences in how countries categorise their social and long-term care spending and Ireland adopts a particularly inclusive definition (Wren et al., 2017).

They must pay a co-payment of $€ 2$ per prescription item, up to a maximum of $€ 20$ per family per month.

For example, those with certain diagnosed conditions (e.g. diabetes) may be eligible for free pharmaceuticals under the Long Term Illness Scheme, and all those under 6, over 70 and with low incomes (but not low enough to qualify for a Medical Card) are entitled to a GP visit card, which provides free GP care. 
At that time (November 1994), the responsibility for providing a dental treatment service to medical cardholders was transferred from publicly-employed dentists to the independent dental sector. The provision of routine dental treatment was available initially to those aged 65+ only, with emergency treatment available for other eligible age groups (Department of Health, 1994; 1999). The next phase of the extension of the DTSS in 1996 provided for routine dental treatment for those aged 16-34, and the provision of full dentures to all medical cardholders without any natural teeth. The extension of routine treatment to the remainder of the eligible Medical Card population was introduced in 1999 (Department of Health, 1999).

Under the DTSS, the Health Service Executive (HSE) provides free dental treatment and appliances to adult medical cardholders and their dependants. Dentists are reimbursed on a fee-per-item basis for DTSS services provided to eligible medical cardholders. These payments are administered by the Primary Care Reimbursement Service (PCRS) unit of the HSE. In 2015, payments to dentists for the provision of dental services and appliances under the DTSS totalled €66.4 million (PCRS, 2016b). 'Above-the-line' procedures, such as oral examinations and relatively simple fillings or restorations can be completed without prior approval of the HSE (albeit with restrictions on the frequency of treatment, e.g. one oral examination per calendar year). Prior approval is required from the HSE for all treatment procedures 'below-the-line' (e.g. prosthetics). ${ }^{5}$ In 2015, a total of 1.3 million adults aged 16+ were eligible for a Medical Card and of these, 30.9 per cent had availed of at least one 'above-the-line' treatment in 2015 (PCRS, 2016a; 2016b). Fee reductions were imposed under the Financial Emergency Measures in the Public Interest Act in 2009, 2011 and 2012 (Department of Health, 2011; Government of Ireland, 2009; 2011; 2012). From April 2010, a number of restrictions were introduced to the DTSS in order to maintain expenditure on the scheme, including the suspension of prophylaxis (cleaning) treatments. ${ }^{6}$ A network of 1,847 self-employed dentists had agreements with the PCRS to provide services under the DTSS in $2015 .^{7}$

For adults (those without Medical Cards), limited dental treatment is available under the Treatment Benefit Scheme (TBS), administered by the Department of Employment Affairs and Social Protection. The TBS provides for an annual examination and prophylaxis for adults who have the required number of pay

See Sections 5.4 and 5.5 of PCRS (2018) for the full list of above-the-line and below-the-line treatments reimbursed under the DTSS.

http://www.hse.ie/eng/staff/PCRS/circulars/Dental/Dental\%20Treatment\%20Services\%20Scheme\%20Budget.pdf [last accessed 7 September 2018]. Since then, prophylaxis treatments have been made available after prior approval, or without prior approval for certain patient groups (e.g. diabetics) (PCRS, 2018).

7 This figure includes 184 dentists who were employed by the HSE and provided services under the DTSS (PCRS, 2016b). 
related social insurance (PRSI) contributions. ${ }^{8}$ In 2015, expenditure on dental treatment under the TBS amounted to $€ 16.6$ million, and a total of 477,658 claims were registered (Department of Social Protection, 2016). ${ }^{9}$

The 1994 Dental Health Action Plan also set out the remit for the PDS. Currently, the PDS provides dental care to children, in addition to services to persons of all ages with special needs (e.g. those receiving care for intellectual disabilities). In 2015 , total expenditure on the PDS amounted to approximately $€ 70$ million (Department of Health, 2016). At present, it is estimated that 90 per cent of the activity of the PDS relates to the provision of services to children, with the remaining 10 per cent accounted for by special care services. ${ }^{10}$ The provision of services to children under the PDS is a school-based approach, with three child dental assessments provided to children between the ages of 5 and 12 (i.e. in primary school), at which stage referral to orthodontic care may be made. In addition, the PDS also provides an emergency service for all children. Under the current service, emergency treatment is generally the only publicly-funded service available for pre-school children (Staines et al., 2016). These services are provided by dentists employed on a salary basis by the HSE in premises owned by the HSE (331 whole-time equivalents as of December 2015) (HSE, 2018).

\subsection{DEVELOPMENT OF THE NATIONAL ORAL HEALTH POLICY}

It is clear therefore that publicly-financed dental services for children, adults and vulnerable groups provide different levels of care in different locations under different schemes and provider payment methods. This system results in gaps in publicly-financed routine care for significant cohorts of the population, including the very young (Staines et al., 2016). One of the key provisions of the new National Oral Health Policy is to establish a re-orientated public dental service for adults with Medical Cards and for children, with a particular focus on the provision of packages of preventive dental care services throughout the life course (Department of Health, 2018b).

The National Oral Health Policy was developed by the Department of Health. In addition to research input by the ESRI, development of the policy was informed by the work of an independent panel with expertise in the areas of oral health services development, and epidemiological, social and economic research. In addition, an Oral Health Policy Academic Reference Group reviewed the current system of dental delivery in Ireland and the national and international literature

The scope of services available to eligible individuals has changed in recent years. For example, Budget 2010 removed the entitlement to one free prophylaxis per calendar year, and this was partially restored in Budget 2018 (each eligible individual now receives a contribution of $€ 42$ towards the cost of one prophylaxis per calendar year). See www.citizensinformation.ie/en/social_welfare/social_welfare_payments/disability_and_illness/treatment_benefit_s cheme.html [last accessed 7 September 2018].

9 It is not clear if the data on claims refer to unique claimants or simply the total number of claims submitted in that year.

10 Department of Health personal communication, 20 September 2017. 
on models of dental delivery (including for special circumstances such as for those in residential care settings, rural or remote settings and marginalised groups) (Woods and Ahern, 2016; Oral Health Policy Academic Reference Group, 2016). ${ }^{11}$ A consultation process was also undertaken, as was a qualitative analysis of interviews with dental healthcare service providers.

The results of the analyses in this report - reviewing the evidence on methods of provider payment in dental care (with a particular focus on emerging methods of provider payment such as bundled methods of payment), and costing the proposed alternative models of delivery of dental care services to adult medical cardholders and children - also informed the development of the policy. Specifically, three key research questions are examined in this report, namely:

1. What is the national and international evidence on the effects of different methods of provider payment on dental healthcare provision and outcomes?

2. What is the estimated cost per annum of providing alternative packages of primary dental healthcare services to all adult medical cardholders?

3. What is the estimated cost per annum of providing alternative packages of primary dental healthcare services to all children aged 0-16?

The following sections present the results of the analyses of each of these three questions in turn.

The cost analysis was conducted, in line with best practice, to assist the Department of Health in assessing the feasibility and affordability of the recommendations outlined in the new National Oral Health Policy and in ascertaining the parameters which are likely to have the largest impact on cost. While a number of alternative scenarios have been examined and a number of assumptions have been made to facilitate this analysis, this analysis is not an end in itself and it is not intended to draw conclusions about the anticipated final cost of the publicly-funded schemes of the new National Oral Health Policy.

In addition, it is important to note that the costing analysis focuses on two key components of the proposed re-orientation of publicly-financed dental healthcare services in Ireland, namely the provision of preventive dental healthcare to adult medical cardholders and to children. The cost of providing other publicly-financed services, such as curative or complex care services, including for other population groups, is not considered in this report (although the implications of the findings for the provision of dental healthcare services to the full population are discussed in Section 6). 


\section{CHAPTER 3}

\section{Provider payment methods - literature review}

\subsection{INTRODUCTION}

In this section we are concerned with payments to providers, and how the financial incentives inherent in different methods of provider payment can help to achieve health policy objectives, e.g. improving population health, making the healthcare system more efficient, effective, equitable, patient-centred, etc. Financial incentives are extrinsic sources of motivation and exist when an individual receives a monetary transfer which is made conditional on acting in a particular way. Intrinsic sources of motivation for healthcare providers include the likelihood that patients' health will improve as a result of a course of action, and motivation from performing a task well. Other sources of motivation include social and peer group norms (Flodgren et al., 2011). It is important to note that the relative impact of sources of intrinsic motivation has a bearing on the effect of financial incentives, and these may vary across providers and settings (Brocklehurst et al., 2013).

\subsection{METHODS OF PROVIDER PAYMENT IN PRIMARY CARE AND DENTISTRY}

\subsubsection{Overview}

Essentially, there are three primary means of reimbursing providers in primary care settings; fee-per-item or fee-for-service (FFS), capitation and salary. Under FFS, providers receive a payment for each item of service provided. FFS payments are tied directly to the amount of services provided, which promotes productivity (Kristiansen and Mooney, 1993). FFS also ensures that access to care is guaranteed, as providers have a direct incentive to see more patients (Jegers et al., 2002). However, FFS may also create incentives towards demand inducement on the part of providers. As FFS payments are retrospectively administered, the uncertainty associated can generate considerable costs for the payer. FFS typically does not offer incentives to improve quality or efficiency or to deliver care that has a low profit margin, such as preventive services or patient education (Steinbrook, 2009).

Under capitation, the provider is paid a fixed fee for the delivery of healthcare services to each registered individual. The payment is usually weighted by characteristics that influence the need for healthcare such as age and gender, and is generally paid prospectively. Capitation payments give providers an incentive to attract and compete for patients, and to introduce preventive measures 
(Christianson and Conrad, 2011). Providers are also incentivised to investigate alternative methods of provision, such as the use of less expensive staff to provide less complex medical services (Robinson, 2001). Capitation may contribute to cost containment by reducing the delivery of unnecessary services and, as financial risk is transferred to providers, is an attractive method from the perspective of governments concerned with escalating healthcare costs. However, if payments to providers are not appropriately risk-adjusted for differences in morbidity, capitation may encourage providers to engage in 'cream-skimming' by selecting only those patients who are expected to generate a low workload (Gosden et al., 2001). Similarly, 'skimping' on care and 'dumping' of high-need patients may also be observed (Ellis, 1998).

In general, salary payments involve a fixed amount of money for a specified time period, thus providing basic income security for providers. Costs are contained as expenditure is known ex ante. Salary payments are administratively easy, and encourage the provider to contain costs (e.g. by offering preventive healthcare services) (Gosden et al., 2000). On the negative side, as the link between payment and performance is weak, salary payments provide incentives for providers to reduce workload in the same manner predicted by capitation payments. Providers have limited opportunities to increase their income (unless allowed to practice privately), which can reduce motivation and effort (Gress et al., 2006). Given the complexity of the incentives generated by each of these three methods of provider payment, choosing between payment methods can be interpreted as a balancing between the conflicting objectives of cost control, quality and access (Blomqvist, 2011).

Indeed, in light of these trade-offs, many countries are now experimenting with mixed or blended methods which include a capitation or salary component as well as FFS or block payments for the provision of certain services (out-of-hours, house calls, etc.). In particular, 'pay for performance' (P4P) elements are being introduced to provider payment schemes in an effort to reward performance that is consistent with health policy objectives (the UK Quality and Outcomes Framework component of the GP contract is a well-known international example) (Roland and Guthrie, 2016). Although assuming a variety of forms, the common characteristic of P4P programmes is the deliberate adoption of explicit payment incentives associated with metrics for specific objectives, such as higher quality processes of care that follow evidence-based guidelines, increased provision of preventive services, better management of chronic diseases, better patient outcomes, etc. (Cashin et al., 2012). Underlying population need also in part determines the choice of most appropriate method; there is some evidence that patients with low needs are best served by capitation, while patients with high needs are best served by FFS (Hennig-Schmidt et al., 2011). 
A recent innovation in healthcare payment is the use of 'bundled payment' methods. The Agency for Healthcare Research and Quality in the US define 'bundled payment' as a method by which payments to healthcare providers are related to the predetermined expected costs of a grouping, or 'bundle' of related healthcare services (Agency for Healthcare Research and Quality, 2011). 'Bundling' therefore refers to the degree to which the components of healthcare are grouped together for payment or paid for separately. Bundled payments may involve single or multiple providers, with most recent applications of bundled payments targeting care coordination across multiple providers. High quality care for patients with chronic and complex conditions often involves coordinating between multiple providers and sources of care. A practical example of a bundled payment would be where a single fee is paid for an entire episode of care; for example, a single fee for hip replacement would cover both the procedure itself and the rehabilitation and follow-up treatments. This fee would be divided among the providers along the care pathway, either prospectively or retrospectively. To date, bundled payments have predominated in settings where the objective is to promote care coordination across healthcare settings and between healthcare providers. i.e. generally only found in acute settings, or in primary care settings that involve coordination with acute services. In most cases, providers are typically given discretion over the allocation of the services used to treat the patient's episode most effectively.

In 2011 in the US Medicare began a new initiative to expand the 'bundled payment' concept to link payments for multiple services that patients receive during an episode of care (Altman, 2012). These initiatives have occurred alongside initiatives in the private sector; see Friedberg et al. (2015) for a review. ${ }^{12}$ Across Europe payments are generally only bundled for care in the acute care setting (hospitals) and then often only for one episode of care with associated outpatient and follow-up activity often being billed separately (Charleston et al., 2012). ${ }^{13}$

On October 1, 2013, the Center for Medicare and Medicaid Innovation officially launched the Medicare Bundled Payment for Care Improvement initiative, a federally-funded initiative mandated by the Affordable Care Act. The Centers for Medicaid and Medicare Services have committed to tying 50 per cent of Medicare payments to these new alternative payment models by the end of 2018. They hope that by paying for related care as part of a broad payment bundle, different providers that treat a patient during a single episode will have incentives to better coordinate care, avoid unnecessary services, and improve patient health outcomes (Cassidy, 2015). single payment for specific healthcare events exclusive of professional (physician) fees. In contrast, bundled care payment models include a single payment for all acute- and post-acute care associated with a hospitalisation or event, inclusive of professional fees. In Ireland, the prospective funding project for primary total hip and total knee replacements commenced as a pilot for activity-based funding in 2011. This initiative implemented prospective funding for primary hip and knee replacements (four diagnosis-related groups (DRGs)) in seven hospitals initially, with a further five hospitals joining six months later as a result of the success of the initial pilot. The hospital budget was reduced by an amount of money related to the four DRGs, and this portion of the budget was 'earned' back, based on work carried out in the hospital. By creating a single price for the individual case (DRG), the responsibility moved to the hospital, so as to ensure that its costs were managed within this price. This required greater clinician engagement, enhanced financial management in hospitals and the development of sustainable 'patient-level costing' 
In terms of provider incentives, bundled methods of payment may exert downward pressure on the unit costs of delivering an episode of care, but they also create incentives to increase the number of cases treated. Although this may indirectly improve access to necessary care, the number of unnecessary services and overall costs also may increase (Cashin et al., 2012). Under prospective payment, services are bundled for payment purposes, creating incentives for providers to limit the services they provide in response to a specific event or illness episode. However, unlike capitation, providers receive more revenue the greater number of episodes they treat (Christianson and Conrad, 2011).

Several types of undesired effects of bundled payments have also been postulated. The most significant potential undesired effects include underuse of effective services within the bundle, avoidance of high-risk patients, and an increase in the number of bundles reimbursed (increasing health spending). Providers under bundled payment may 'game' the system by changing coding practices to maximise payment for the bundle ('upcoding') or by moving services in time or location to qualify for separate payments ('unbundling') (Agency for Healthcare Research and Quality, 2011; Porter and Kaplan, 2016; Conrad, 2015). One significant concern with bundled payment methods is that providers may achieve savings not just by forgoing wasteful or redundant care but by not furnishing needed care or choosing the cheapest alternative (Cassidy, 2015).

\subsubsection{Empirical evidence in primary care}

In terms of empirical evidence, a number of systematic reviews of provider remuneration in primary care have been undertaken (Giuffrida et al., 1999; Scott et al., 2011; Gosden et al., 2000; 2001), with results generally in line with the theoretical predictions (e.g. FFS leads to a higher quantity of primary care services compared with capitation and salary provider payment methods). A common finding was the poor quality of the evidence available with which to identify the causal effect of provider payment on the outcomes of interest (e.g. health expenditure, patient outcomes, service quality, etc.). For example, Flodgren et al. (2011), who conducted an overview of four systematic reviews that evaluated the impact of financial incentives on provider behaviour and patient outcomes, found evidence that while financial incentives may be effective in changing provider behaviour, the evidence had serious methodological limitations, with limited generalisability outside of the particular study contexts.

The quality of the evidence is also an issue in learning from previous international experience with P4P schemes. For example, Nolan et al. (2011) reviewed the 
international evidence on P4P and assessed its potential applicability in the Irish context. They highlighted the poor quality of evidence on P4P schemes, stemming partly from technical challenges inherent in evaluating P4P schemes (e.g. lack of a control group). Notwithstanding these technical difficulties, they concluded that the available evidence does not provide a clear answer to the question of whether P4P should be implemented. Limitations identified included difficulties in obtaining valid performance indicators, unintended consequences (e.g. crowding out of intrinsic motivation on the part of providers), and the absence of evidence on cost effectiveness of P4P schemes. More recent overviews of P4P by Ogundeji et al. (2016) and Cashin et al. (2012) have confirmed that the evidence that P4P improves health outcomes, or even the quality of processes of care, is limited at best.

In terms of empirical evidence on bundled payment methods, the Agency for Healthcare Research and Quality reviewed 58 studies on bundled payments published between 1985 and 2011, largely from the US (Agency for Healthcare Research and Quality, 2011). In particular, they wanted to analyse what the evidence showed on the effects of bundled payment versus usual (predominantly FFS) payment on healthcare spending and quality measures. They found that, in general, the transition from a cost-based or FFS reimbursement to bundled payment was associated with a decline in spending of 10 per cent or less. Bundled payment was also associated with a decrease in the utilisation of services included in the bundle, often measured as reductions in length of stay or utilisation of specific services. However, the introduction of bundled payment was associated with inconsistent and generally small effects on quality measures. Most of the studies reviewed were single-setting (usually in-patient) that replaced FFS reimbursement systems in Medicare or other public insurance systems. They highlighted that the strength of the evidence on bundled payments was low, reflecting the difficulty in evaluating large-scale policy interventions that occur in a rapidly-changing healthcare environment. They noted that the most rigorous study designs were usually feasible only when policymakers planned for an evaluation experiment in the course of experimentation.

Focusing on the one application included in the Agency for Healthcare Research and Quality Review that was relevant outside of a hospital setting, Rosenthal (1999; 2000) examined the impact of a contracting change within a managed behavioural health organisation in the US providing outpatient mental healthcare services, from a FFS system to a case-rate system, with utilisation management delegated to providers. The contracting change resulted in a 25 per cent reduction in mental health visits per episode. The effect varied with the amount of payment and was more pronounced for providers with a larger share of revenue from risk contracts and with intensive utilisation management programmes. They found no evidence of patient selection on the part of participating providers, i.e. selecting 
low risk patients. However, they noted that the effects may be biased upwards, as providers who chose the new contracting arrangements may have been very different from those who remained on the existing FFS contracts. Unfortunately they could not assess the impact of the contracting change on outcomes other than utilisation, such as patient health, and noted that spill-over effects on pharmacy and other primary care costs were possible.

\subsubsection{Empirical evidence in dental care}

Brocklehurst et al. (2013) undertook a systematic review of different methods of provider payment (i.e. FFS, salary, capitation, blended) on the level and mix of activities provided by primary care dentists and the impact on patient outcomes. Based on the findings from two randomised control trials (RCTs) conducted in the UK (Clarkson et al., 2008; Coventry et al., 1989), they concluded that financial incentives as part of remuneration systems may produce changes to clinical activity undertaken by primary care dentists, although the quality of the evidence available was poor. They therefore recommended further experimental research, with particular attention paid to the impact of provider payment on patient outcomes.

A number of other studies have examined the impact of provider payment on the behaviour of dentists, albeit using non-experimental evidence. For example, a series of papers from Norway examined the impact of a policy change in 2000 whereby all dentists in one county were given the opportunity to change their contract from a fixed salary contract to a combined per capita and fixed salary contract. Comprehensive data were collected before and after the change. They found that the transition led to an increase in the number of individuals registered with each dentist without either a fall in quality or a patient selection effect (Grytten et al., 2009; 2013).

In 2006 the existing FFS system for National Health Service (NHS) dental healthcare services in England and Wales was replaced by three 'course of treatment' payment bands. As a result many items of treatment that previously carried different fee levels were paid the same amount. Tickle et al. (2011) carried out a descriptive analysis of treatment trends before and after the introduction of the new dental contract. They found that dentists shifted activity towards treatments where rewards were high relative to costs, i.e. the mix of service types changed rapidly with services that required less dentist time (e.g. extractions) 'replacing' services that required more dentist time (e.g. fillings). Chalkley et al. (2010) evaluated the impact of the change by comparing activity in England and Wales with a sample of control dentists in Scotland where the contract did not change. They found that dentists who were previously on FFS contracts did not display a statistically significant response to the shift to activity-based payment, but dentists who were previously on quasi-employment contracts exhibited a 
statistically significant increase in their public service provision. Focusing on the Scottish situation, where dentists are reimbursed either via salary or via a predominately FFS system, Listl and Chalkley (2014) found that a significantly higher utilisation of examinations was observed if dentists were paid FFS compared with salary, but this was largely accounted for by the characteristics of dentists themselves rather than the payment method. ${ }^{14}$

More recently in Northern Ireland, Hill et al. (2017) compared outcomes in 13 practices paid by capitation with those in 57 control practices paid by FFS along a number of dimensions (patient selection, service coverage, type and mix of treatments, and system financial viability). They found evidence that the capitation practices were significantly less likely to register older people and patients exempt from payment charges (both groups would be expected to have higher dental healthcare needs). They also found that capitation practices saw a smaller proportion of their registered patients and provided treatment courses that were of lower monetary value, although there was no evidence that they 'underserved' their patients in the form of differences in the average number of treatments provided per registered patient. There was evidence of differences in treatment mix between the two sets of practices with capitation practices providing fewer examinations, fillings and scale and polishes, but more extractions than FFS practices. However, there was no difference in the extent of preventive activity (i.e. fluoride varnishes and fissure sealants) between practices. There were no differences in mean monthly payment charge revenue between practices. In Ireland, Woods et al. (2010) examined the impact of a change in the administration and remuneration arrangements under the DTSS in 1999. Using data from the PCRS over the period June 1996 to April 2005, they found that there was a substitution away from extractions towards amalgam fillings following the fee increase for amalgams (from €20.33 to €33.72) in 1999.

Focusing on P4P initiatives in dentistry, Cornejo-Ovalle et al. (2015) evaluated the impact of a P4P programme (as an addition to the existing salary payment) among dentists in Santiago, Chile on care provided to 6-year-old children over a five-year period spanning the introduction of P4P incentives (2006-2010). They found that on average, when P4P was implemented, there was a significant increase in activity when compared to the time period in which P4P was not used. VoineaGriffin et al. (2010) reviewed a number of P4P schemes in the US that attempted to link remuneration to provider performance in dental care; they found limited evidence of effectiveness, partly due to the lack of rigorous evaluations of existing P4P programmes. In addition, they discussed the difficulty in measuring quality in dental care, an issue that must be addressed before P4P initiatives can be 
considered in dental care. Grytten (2017) also highlighted the difficulty in implementing P4P in dental care, in the absence of agreed clinical indicators of the severity of dental diseases.

With the exception of the studies by Chalkley et al. (2010) and Tickle et al. (2011) which evaluated the move to a predominately activity-based reimbursement system in the NHS in the late 2000s (which has similarities with bundling), there is little published research of a bundled payment system in dental care. However, there are some examples of emerging initiatives in non-acute settings that provide some initial suggestive evidence on the possible effects of bundled payment methods in these settings. For example, de Bakker et al. (2012) and Struijs and Baan (2011) carried out an evaluation of a 2007 bundled care programme in diabetes care in the Netherlands ${ }^{15}$ and found that the introduction of bundled payments and care groups had both positive and negative effects, as well as some unintended consequences (e.g. potential conflicts of interest between care organisations who were also GPs providing services). The positive consequences were better collaboration, better process quality (e.g. adherence to protocols), and more transparency. The negative consequences were dominance of the care groups by GPs, large price variations that were only partially explained by differences in the provision of care (suggesting that providers had very different interpretations of the services included in the bundle, i.e. 'stinting' on care), and administrative burden (e.g. in apportioning payments across providers). The effects on patient outcomes such as blood sugar levels and costs were unknown.

\subsection{SUMMARY}

In terms of provider payment in primary care (and dentistry), the optimal mix between FFS, capitation and salary is still open to question. It is important to recognise that no single payment method can achieve all desired policy objectives as there are trade-offs involved in favouring one method over another. It is also important to note that the extent to which providers are influenced by the way in which they are paid is dependent on the strength of the different factors motivating their behaviour (e.g. self-interest, patients' interest, medical ethics, etc.).

15 The diabetes example was subsequently extended (on a voluntary basis) in the Netherlands in 2010 to care for other chronic conditions such as chronic obstructive pulmonary disease (COPD). In the diabetes application, health insurers paid a single fee for a principal contracting organisation (a new legal entity called a care group) to cover all elements of primary care for patients with diabetes. Care groups consisted of multiple healthcare providers and were generally owned by GPs. The main objective of the programme was to reduce fragmentation in care across providers of care. Services in the care bundles were fully covered by the basic insurance that is mandatory for all Dutch citizens, which meant that these services required no additional payment from patients. Care standards specified only the treatment activities; in an attempt to encourage competition among providers, the standards did not specify the discipline of the provider who should provide the care. 
While P4P components are attractive and many countries have experimented with various different P4P initiatives, their success is dependent on the accuracy with which outcomes can be measured. In particular, the difficulty in measuring clinical outcomes in dentistry has been highlighted (Grytten, 2017). In an effort to overcome some of the limitations of capitation or similar prospective payment methods, many countries are now experimenting with bundled payment initiatives. Initially, they have been developed in acute settings in order to improve care coordination across multiple providers of care. As these initiatives are still in the development or pilot phase in many countries, they have not yet been subject to rigorous evaluations of their impacts on efficiency, access, quality and patient health outcomes. 



\section{CHAPTER 4}

\section{Costing dental healthcare services (adult medical cardholders)}

\subsection{INTRODUCTION}

As noted, the National Oral Health Policy proposes the reorientation of services for adult medical cardholders under the DTSS with a new focus on preventive services (Department of Health, 2018b). Table 4.2 sets out the existing list of treatments and fees payable to dentists under the DTSS, while Table 4.1 summarises the alternative dental healthcare services proposed under the new policy. ${ }^{16}$ The purpose of this section is to outline the data and methods used to assess the public expenditure implications of providing an alternative preventive dental healthcare package to adult medical cardholders. Estimates are provided for a range of alternative scenarios that reflect uncertainty in key assumptions (e.g. around population take-up), future technological developments (e.g. phasing out of mercury fillings) and policy parameters (e.g. frequency of recommended services).

\section{Dental Treatment}

Oral examination including assessment of hard and soft tissue for oral cancer, oral surgery, orthodontics; radiographs/scans; biopsies; prescriptions

Prophylaxis (scale and polish)

Fissure sealants

Fluoride varnish

High fluoride prescription toothpaste

Source: Department of Health (2018b).

16 The alternative preventive dental healthcare packages contain some services that are reimbursed under the current FFS arrangement (e.g. amalgam fillings), while others are new (e.g. fissure sealants). See also Table 4.2. Not all services are preventive per se, and so the packages may be considered as reflecting a set of preventive and core services. 
TABLE 4.2 EXISTING TREATMENTS AND SCHEDULE OF FEES UNDER THE DTSS (ADULT
MEDICAL CARDHOLDERS)

\begin{tabular}{|c|c|}
\hline Treatment & $€$ \\
\hline Oral examination & 33.00 \\
\hline Prophylaxis & 31.00 \\
\hline Restoration/filling (amalgam) & 50.06 \\
\hline Restoration/filling (composite - six anterior teeth only) & 51.88 \\
\hline Exodontics (extraction under local anaesthetic) & 39.50 \\
\hline \multicolumn{2}{|l|}{ Surgical extraction - maximum 2 units: } \\
\hline Fee payable for each 15 minute unit & 35.00 \\
\hline Maximum payable & 70.00 \\
\hline First stage endodontic treatment (anterior teeth only) & 57.30 \\
\hline \multicolumn{2}{|l|}{ Denture repairs: } \\
\hline First item of repair & 47.86 \\
\hline Each subsequent item & 15.34 \\
\hline Maximum payable & 78.54 \\
\hline Apicectomy/amputation of roots & 168.70 \\
\hline Endodontics (anterior teeth only) & 137.66 \\
\hline Protracted periodontal treatment per visit ( $\max 4)$ & 26.36 \\
\hline Miscellaneous (e.g. haemorrhage or prescriptions only) & 22.65 \\
\hline \multicolumn{2}{|l|}{ Prosthetics } \\
\hline Full upper or lower dentures (other than edentulous persons) & 326.22 \\
\hline Partial upper or lower acrylic denture & 239.27 \\
\hline Complete upper or lower recline & 130.59 \\
\hline Complete upper and lower recline & 217.38 \\
\hline Full upper and lower dentures (edentulous persons only) & 478.74 \\
\hline
\end{tabular}

Source: PCRS (2016b).

\subsection{DATA AND METHODS}

In order to assess the implications for public expenditure on the proposed package of services for adult medical cardholders, a number of pieces of information are necessary (see Table 4.3):

1. Price per unit of each service in the preventive care package;

2. Eligible population for each service;

3. Proportion of eligible population who may be expected to avail of the service;

4. Usage frequency of each service (e.g. one oral examination per annum). 


\begin{tabular}{|c|c|c|c|c|}
\hline $\begin{array}{l}\text { Preventive Dental } \\
\text { Treatment }\end{array}$ & $\begin{array}{l}\text { Price per } \\
\text { unit } \\
€\end{array}$ & $\begin{array}{c}\text { Eligible Medical Card } \\
\text { Population }\end{array}$ & $\begin{array}{c}\text { Take-Up } \\
\%\end{array}$ & $\begin{array}{l}\text { Usage } \\
\text { Frequency }\end{array}$ \\
\hline \multirow{4}{*}{$\begin{array}{l}\text { Oral examination including } \\
\text { assessment of hard and soft } \\
\text { tissue for oral cancer, oral } \\
\text { surgery, orthodontics; } \\
\text { radiographs/scans; biopsies; } \\
\text { prescriptions }\end{array}$} & \multirow{4}{*}{33.00} & $\begin{array}{l}\text { Aged } 16-24 \\
n=170,146\end{array}$ & 30.9 & Annual \\
\hline & & $\begin{array}{l}\text { Aged 25-69 ('low risk' })^{1} \\
\qquad n=739,650\end{array}$ & 30.9 & Biennial \\
\hline & & $\begin{array}{c}\text { Aged 25-69 ('high risk') } \\
\text { n=100,861 }\end{array}$ & 30.9 & Annual \\
\hline & & $\begin{array}{l}\text { Aged } 70+ \\
n=333,466\end{array}$ & 30.9 & Annual \\
\hline $\begin{array}{l}\text { Prophylaxis (scale and } \\
\text { polish) }\end{array}$ & 31.00 & $\begin{array}{l}\text { Aged } 16+\text { (non-edentulous) } \\
\qquad n=1,233,682\end{array}$ & 30.9 & Annual \\
\hline Fissure sealants & $50.06^{2}$ & $\begin{array}{c}\text { Aged } 16-24 \\
n=170,146\end{array}$ & 30.9 & $\begin{array}{l}\text { One treatment } \\
\text { during age } \\
\text { range } 16-24^{3}\end{array}$ \\
\hline Fluoride varnish & 22.65 & $\begin{array}{l}\text { Aged } 65+\text { (non-edentulous) in } \\
\text { non-fluoridated areas }{ }^{4} \\
n=51,087\end{array}$ & 30.9 & Annual \\
\hline $\begin{array}{l}\text { High fluoride prescription } \\
\text { toothpaste }\end{array}$ & 22.65 & $\begin{array}{c}\text { Aged } 16-24 \text { and } 65+ \\
\text { (non-edentulous) in } \\
\text { non-fluoridated areas } \\
\quad n=78,310\end{array}$ & 30.9 & Annual \\
\hline
\end{tabular}

Sources: See Section 4.2 for further details.

Notes: $\quad$ 1. The Department of Health estimate that 88 per cent of the 25 - to 69-year-old age group are 'low risk', i.e. requiring one oral examination every two years, and 12 per cent of the 25- to 69-year-old age group are 'high risk', i.e. requiring one oral examination every year (Department of Health, personal communication, 13 February 2017).

2. The cost of a fissure sealant treatment is based on the fee for an amalgam filling, $€ 50.06$ (Department of Health, personal communication, 2 November 2016).

3. It is assumed that eligible individuals will need to avail on one fissure sealant treatment during the nine-year period from age 16-24 (Department of Health, personal communication, 13 February 2017).

4. Data on the proportion of the population living in fluoridated areas are taken from O'Sullivan and O'Connell (2015). Using data from the 2006 Census of Population, they report that 84 per cent of households have fluoridated water supplies.

\begin{abstract}
Where possible, we use data for 2015. Data on the price per unit of each recommended service, and on the eligible population for each service, are sourced from the PCRS Statistical Analysis of Claims and Payments 2015 (PCRS, 2016b). ${ }^{17}$ The eligible population for prophylaxis, fillings, fluoride varnish and high fluoride prescription toothpaste excludes the estimated 25.7 per cent of the over 65s Medical Card population who are edentulous, and who are assumed will not need these services. ${ }^{18}$ In addition, not all eligible individuals will be expected to
\end{abstract}

17 Price per unit is sourced from 'Scale of Fees Payable under the Dental Treatment Services Scheme as at 31 December $2015^{\prime}$ (p.208). See also Table 4.2 of this report. Numbers of medical cardholders are sourced from Table 7 (pp. 30-35).

18 The Oral Health of Irish Adults 2000-2002 study reported an edentulous rate of 45.6 per cent among over 65 medical cardholders in 2000-2002; see Table 3.2 in Whelton et al. (2007). The data were collected from a detailed clinical oral examination. The Department of Health have produced projections of edentulous rates out to 2046, using data on past trends in edentulous rates. Three alternative assumptions about the annual rate of decline in edentulous rates 
avail of the services offered. In 2015, 30.9 per cent of eligible medical cardholders availed of 'above-the-line' treatments under the DTSS, which includes oral examinations, prophylaxis, fillings, etc. ${ }^{19}$ We therefore assume that the eligible population is adjusted downwards to account for this average take-up. ${ }^{20}$ In sensitivity analyses (detailed below), we assess the implications for expenditure of varying the estimated take-up of preventive dental healthcare services under the DTSS.

Data on the usage frequency of each service (e.g. one oral examination per annum) were provided by the Department of Health. For those aged 25-69 years of age who are deemed to be 'low risk', an oral examination every two years is recommended. For those aged 16-24, one treatment of fissure sealants (i.e. for two teeth) is recommended during that age range. Further details are provided in Table 4.3. For all other treatments, a usage frequency of once per annum is assumed. In further sensitivity analyses (detailed below), we model the implications for expenditure of changing the usage frequency of selected services to every two or every four years.

\subsection{SENSITIVITY ANALYSES}

We then run a number of separate additional analyses to test the sensitivity of our estimates of public expenditure to variations in our underlying assumptions and policy parameters. For example, what is the impact of assuming greater takeup of services under each preventive care package? What is the impact of requiring all fillings to be composite rather than amalgam? What is the impact of providing services on a biennial rather than an annual basis?

We run six sensitivity analyses as follows:

1. Assuming that all those eligible receive two treatments of fissure sealants per annum, rather than one treatment;

2. Assuming increased take-up of services. The estimate of increased take-up we use is the proportion of those in the lowest income quintile who have at least one visit to a dentist in the last year (38 per cent), obtained from the 2007 Survey of Lifestyles, Attitudes and Nutrition in Ireland (SLAN). ${ }^{21}$

(2, 4 and 6 per cent) are used in these projections. We use the figure for the midpoint scenario (i.e. an annual decline of 4 per cent), which results in a projected edentulous rate of 25.7 per cent in 2015. 2016b). At the end of December 2015, 415,557 of these individuals had availed of 'above-the-line' DTSS treatment in 2015 (PCRS, 2016a), which equates to an average take-up rate of 30.9 per cent. treatment is not available from the PCRS but rather the number of unique 'above-the-line' and 'below-the-line' patients only. We therefore assume the average 'above-the-line' take-up applies for all treatments in the alternative preventive dental healthcare packages. 
3. Assuming that the eligible population is entitled to an oral examination, prophylaxis, fluoride varnish and high fluoride prescription toothpaste once every two years; ${ }^{22}$

4. Assuming that the eligible population is entitled to an oral examination, prophylaxis, fluoride varnish and high fluoride prescription toothpaste once every four years. ${ }^{22}$

5. Assuming that one filling per annum is allowed. ${ }^{23}$

6. Assuming that one composite filling per annum is allowed. ${ }^{24}$

\subsection{RESULTS}

We present first the results for the baseline scenario in Table 4.4. The estimated annual expenditure on the alternative preventive dental healthcare package is $€ 23.0$ million. Reflecting the proposed availability of these services to the majority of the population of adult medical cardholders on an annual basis, the costs of providing examinations and prophylaxis account for the largest components of total cost (€9.9 million and €11.8 million respectively).

\begin{tabular}{l|c}
\hline & Emillion \\
\hline $\begin{array}{l}\text { Oral examination including assessment of hard and soft tissue for oral cancer, oral } \\
\text { surgery, orthodontics, radiographs/scans, biopsies, prescriptions }\end{array}$ & 9.9 \\
\hline Prophylaxis (scale and polish) & 11.8 \\
\hline Fissure sealants & 0.3 \\
\hline Fluoride varnish & 0.4 \\
\hline High fluoride prescription toothpaste & 0.5 \\
\hline Total & 23.0 \\
\hline
\end{tabular}

Source: Author's analysis.

Note: $\quad$ Underlying assumptions: Price per unit, eligible population, take-up and usage frequency as per Table 4.3.

These estimates are most sensitive to alternative assumptions about the scope of services offered, and to a lesser extent by assumptions about take-up and the usage frequency of the specified services. Allowing for one filling per annum increases annual expenditure to $€ 42.3$ million. Assuming an increased take-up to 38 per cent of the eligible population increases annual expenditure to

22 The exception is fissure sealants where the recommended incidence does not change, i.e. one treatment during age range $16-24$ years.

23 We assume that the existing split between amalgam and composite fillings in 2015 applies (i.e. 65.5 per cent of all fillings under the DTSS in 2015 were amalgam, and 34.5 per cent were composites) (PCRS, 2016a). The relative ratio between amalgams and composites varies by age (e.g. from 80:20 in the 16- to 24-year-old age group, to 40:60 in the over 75s), but we take the average across all those aged $16+$ here.

24 The EU signed the Minamata Convention on Mercury in October 2013 and thereby committed to ensure its ratification and implementation across the Union.

See http://ec.europa.eu/environment/chemicals/mercury/ratification_en.htm for further details [last accessed 7 September 2018]. 
$€ 28.2$ million. Assuming that eligible individuals (i.e. those aged 16-24) avail of two fissure sealant treatments rather than one treatment raises annual expenditure to $€ 23.3$ million. Assuming that the eligible population receives the specified services every two (four) years, rather than annually, reduces annual expenditure to $€ 13.5$ million ( $€ 6.9$ million). The results of the sensitivity analyses are presented in Table 4.5.

\begin{tabular}{|c|c|c|c|c|c|c|}
\hline & \multicolumn{6}{|c|}{ Emillion } \\
\hline & (1) & (2) & (3) & (4) & (5) & (6) \\
\hline $\begin{array}{l}\text { Oral examination including assessment of hard and soft } \\
\text { tissue for oral cancer, oral surgery, orthodontics, } \\
\text { radiographs/scans, biopsies, prescriptions }\end{array}$ & 9.9 & 12.2 & 6.9 & 3.4 & 9.9 & 9.9 \\
\hline Amalgam filling & & & & & 12.5 & - \\
\hline Composite filling & & & & & 6.8 & 19.8 \\
\hline Prophylaxis (scale and polish) & 11.8 & 14.5 & 5.9 & 3.0 & 11.8 & 11.8 \\
\hline Fissure sealants & 0.6 & 0.4 & 0.3 & 0.3 & 0.3 & 0.3 \\
\hline Fluoride varnish & 0.4 & 0.4 & 0.2 & 0.1 & 0.4 & 0.4 \\
\hline High fluoride prescription toothpaste & 0.5 & 0.7 & 0.3 & 0.1 & 0.5 & 0.5 \\
\hline Total & 23.3 & 28.2 & 13.5 & 6.9 & 42.3 & 42.8 \\
\hline
\end{tabular}

Source: Author's analysis.

Notes: Alternative scenario assumptions:

1. Fissure sealants: two treatments (four fissure sealants), i.e. $€ 100.12$

2. Increased take-up among the eligible population, i.e. 38 per cent for all treatments.

3. Usage frequency of all services (every two years). The exception is fissure sealants where the usage frequency does not change, i.e. one treatment during age range 16-24 years.

4. Usage frequency of all services (every four years). The exception is fissure sealants where the usage frequency does not change, i.e. one treatment during age range $16-24$ years.

5. Allowing for one filling per annum, assuming the existing (2015) split between amalgam and composite fillings, i.e. $65 / 35$

6. Allowing for one filling per annum, assuming all fillings are composites.

Combining the data in Tables 4.1 and 4.3 , it is possible to generate indicative estimates of the cost of the care packages for particular population groups. The results of this exercise are presented in Table 4.6 and illustrate that, for example, the cost of the provision of a preventive dental healthcare package to a 16- to 24year-old medical cardholder in a non-fluoridated area would be €92.21 per annum. The variation across age groups and areas reflects the variation in the scope of services recommended for each group. For example, a dentist treating a young adult living in a non-fluoridated area would receive €92.21 per annum for the provision of services to this young adult, in comparison to the $€ 69.56$ they would receive for a similar young adult living in a fluoridated area. 
TABLE 4.6 APPROXIMATE PACKAGE PAYMENT BY AGE GROUP (BASELINE SCENARIO, ADULT MEDICAL CARDHOLDERS)

\begin{tabular}{|l|c|c|}
\hline \multicolumn{1}{|c|}{ Age Group } & Fluoridated Area & Non-Fluoridated Area \\
\hline $\mathbf{1 6 - 2 4}$ & $€$ & 69.56 \\
\hline $\mathbf{2 5 - 6 4}$ (low risk) & 47.50 & 92.21 \\
\hline $\mathbf{2 5 - 6 4}$ (high risk) & 47.50 & 47.50 \\
\hline $\mathbf{6 5 - 6 9}$ (low risk) & 64.00 & 92.80 \\
\hline $\mathbf{6 5 - 6 9}$ (high risk) & 64.00 & 64.00 \\
\hline $\mathbf{7 0 +}$ & 64.00 & 109.30 \\
\hline
\end{tabular}

Source: Author's analysis.

Note: $\quad$ Price per unit, eligible population, take-up and usage frequency as per the baseline scenario (see Table 4.3 for included services). 



\title{
CHAPTER 5
}

\section{Costing dental healthcare services (children)}

\begin{abstract}
$5.1 \quad$ INTRODUCTION
Under the National Oral Health Policy, it is proposed to have an assessment of each child's oral health in the first two years of life, and to offer an expanded preventive and curative dental healthcare package at three key age ranges $(2-5,6$ 11 and 12-15) (Department of Health, 2018b). It is envisaged that services will be delivered in independent dental practices (akin to the DTSS), and that dental practitioners would enter into contract with the HSE to provide these services. The scope of existing service provision for children up to 16 years of age under the Public Dental Service (PDS) is outlined in Table 5.1. Under the proposed system, dentists would be reimbursed for a package of services as outlined in Table 5.2.
\end{abstract}

TABLE 5.1 EXISTING TREATMENTS FOR CHILDREN UNDER THE PUBLIC DENTAL SERVICE (PDS)

\begin{tabular}{|l|l|}
\hline \multicolumn{1}{|c|}{ Age Group } & \multicolumn{1}{c}{ Treatment } \\
\hline All children 5-12 & Three assessments, with referral for further treatment if necessary \\
\hline All children 0-15 & Emergency care
\end{tabular}

Source: Department of Health (2018b).

TABLE 5.2 PROPOSED DENTAL HEALTHCARE SERVICES FOR CHILDREN

\begin{tabular}{l|l|l|}
\hline \multicolumn{1}{|c|}{ Age Group } & \multicolumn{1}{c|}{ Dental Treatment } & \multicolumn{1}{c|}{ Delivery Setting } \\
\hline $\begin{array}{l}\text { 0-1 } \\
\text { (i.e. up to 2nd birthday) }\end{array}$ & Assessment & Independent practice \\
\hline $\begin{array}{l}\text { 2-5 } \\
\text { (i.e. up to 6th birthday) }\end{array}$ & Examination & Independent practice \\
\hline $\begin{array}{l}\text { 6-11 } \\
\text { (i.e. up to 12th birthday) }\end{array}$ & Filling & Independent practice \\
\hline $\begin{array}{l}\text { 12-15 } \\
\text { (i.e. up to 16th birthday) }\end{array}$ & Filling & Independent practice \\
\hline & Fissure sealants & Independent practice \\
\hline & Filling & Independent practice \\
\hline
\end{tabular}

Source: Department of Health (2018b).

As in Section 4, the purpose of this section is to outline the data and methods used to assess the public expenditure implications of providing an alternative preventive dental healthcare package to children. Estimates are provided for a range of alternative scenarios that reflect uncertainty in key assumptions (e.g. 
around population take-up), public health advice (e.g. provision of fluoride therapy to young children) and policy parameters (e.g. frequency of recommended services).

\subsection{DATA AND METHODS}

As with the analysis for adult medical cardholders, in order to assess the implications for public expenditure on these alternative packages of services for children, a number of pieces of information are necessary (see Table 5.3):

1. Price per unit of each service;

2. Eligible population for each service;

3. Proportion of eligible population who may be expected to avail of the service;

4. Usage frequency of each service (e.g. one assessment before the child's second birthday).

Data for 2015, or the nearest available year, are used. Data on the price per unit of each recommended service are sourced from the PCRS Statistical Analysis of Claims and Payments 2015 (PCRS, 2016b). ${ }^{25}$ In sensitivity analysis, detailed below, we consider the implications of changing the price per unit by changing the skill mix for the delivery of certain services, e.g. from a dental surgeon to a dental hygienist or nurse.

Data on the eligible population are sourced from the Central Statistics Office (CSO). For some services, the eligible population is a subset of the entire population in that age range. For example, fluoride therapy is assumed to be available only to those residing in non-fluoridated areas. Data on the proportion of households living in non-fluoridated areas are taken from O'Sullivan and O'Connell (2015), using data from the 2011 Census of Population. Similarly, not all children will need to avail of interventions such as fillings; we use data from the Fluoride and Caring for Children's Teeth (FACCT) study of 5- and 12-year-olds in Dublin, Cork and Kerry in 2013/2014, to restrict the eligible population for fillings to those children with at least one decayed, missing or filled tooth (DMFT>0). ${ }^{26}$

25 Price per unit was sourced from 'Scale of Fees Payable under the Dental Treatment Services Scheme as at 31 December 2015' (p.208) (PCRS, 2016b).

26 Tooth decay levels in children are best described using a measurement called the decayed, missing or filled tooth (DMFT) index. This measurement counts the number of teeth which are decayed (D), missing (i.e. extracted due to decay) (M), or filled due to decay (F). For young children with primary teeth only, the convention is to use lower case letters ( $\mathrm{dmft}$ ). For older children with permanent teeth only, the convention is to use upper case letters (DMFT) (Whelton et al., 2006). In this report, we use the term DMFT to refer to both DMFT and dmft. 

BASELINE SCENARIO (CHILDREN)

\begin{tabular}{|c|c|c|c|c|c|c|}
\hline Age Group ${ }^{1}$ & $\begin{array}{c}\text { Dental } \\
\text { Treatment }^{1}\end{array}$ & $\begin{array}{c}\text { Price per } \\
\text { unit }^{2} \\
€\end{array}$ & $\begin{array}{c}\text { Eligible } \\
\text { Population } \\
\text { (description) }^{1}\end{array}$ & $\begin{array}{c}\text { Eligible } \\
\text { Population } \\
\text { (n) }\end{array}$ & $\begin{array}{c}\text { Take-Up } \\
\%\end{array}$ & $\begin{array}{c}\text { Usage } \\
\text { Frequency } \\
\text { for Age } \\
\text { Group }^{1}\end{array}$ \\
\hline $\begin{array}{l}0-1 \\
\text { (i.e. up to 2nd } \\
\text { birthday) }\end{array}$ & Assessment & 33.00 & All children 0-1 & 130,435 & 83.1 & Once \\
\hline \multirow{2}{*}{$\begin{array}{l}2-5 \\
\text { (i.e. up to 6th } \\
\text { birthday) }\end{array}$} & Examination & 33.00 & All children 2-5 & 280,389 & 83.1 & Twice \\
\hline & Filling & 51.88 & $\begin{array}{l}\text { All children } 2-5 \\
\text { with } \mathrm{DMFT}>0^{4}\end{array}$ & 83,276 & 83.1 & Twice \\
\hline \multirow{4}{*}{$\begin{array}{l}6-11 \\
\text { (i.e. up to 12th } \\
\text { birthday) }\end{array}$} & Examination & 33.00 & All children 6-11 & 404,772 & 83.1 & Three times \\
\hline & Filling & 51.88 & $\begin{array}{l}\text { All children 6-11 } \\
\text { with DMFT>04 }\end{array}$ & 134,384 & 83.1 & Twice \\
\hline & $\begin{array}{l}\text { Fissure } \\
\text { sealants }\end{array}$ & 50.06 & All children 6-11 & 404,772 & 83.1 & Twice \\
\hline & $\begin{array}{l}\text { Fluoride } \\
\text { therapy }\end{array}$ & 22.65 & $\begin{array}{c}\text { All children 6-11 } \\
\text { in non-fluoridated } \\
\text { areas }^{5}\end{array}$ & 64,764 & 83.1 & Three times \\
\hline \multirow{2}{*}{$\begin{array}{l}12-15 \\
\text { (i.e. up to 16th } \\
\text { birthday) }\end{array}$} & Examination & 33.00 & All children 12-15 & 246,702 & 83.9 & Twice \\
\hline & Filling & 51.88 & $\begin{array}{l}\text { All children } 12-15 \\
\text { with } D M F T>0^{4}\end{array}$ & 90,540 & 83.9 & Twice \\
\hline
\end{tabular}

Source: See Section 5.2 for further details.

Notes: 1.Data on the proposed treatments for each age group, and the recommended usage frequency for these treatments, were provided by the Department of Health (Department of Health, personal communications, 20 September 2017; 22 November 2017; 24 November 2017; 27 November 2017).

2. Prices per unit for assessment/examinations, extractions, fillings and fluoride therapy are sourced from the current schedule of fees payable to dentists under the DTSS; see p.208 of PCRS (2016b) for details. The cost of a fissure sealant treatment (two teeth) is based on the fee for an amalgam filling, $€ 50.06$ (Department of Health, personal communication, 2 November 2016).

3. Data on the expected take-up of services are sourced from Wave 1 (nine years of age) and Wave 2 ( 13 years of age) of the Child Cohort of the Growing Up in Ireland study of children. The proportion of children at nine years of age with at least one dental visit over a two-year period is used to proxy average take-up of children up to the age of 12 , while the proportion of children at 13 years of age with at least one dental visit over a two-year period is used to proxy average take-up in children over the age of 12.

4. Data on the proportion of children with at least one decayed, missing or filled tooth (DMFT) are used to proxy the number of children who may be expected to avail of fillings. These data are sourced from data provided by the Department of Health from the Fluoride and Caring for Children's Teeth (FACCT) study of 5- and 12-year-olds in Dublin, Cork and Kerry in 2013/2014 (Department of Health, personal communication, 20 September 2017).

Not all eligible individuals will be expected to avail of the services offered. For each age range, the core preventive service (assessment/examination) is to be provided approximately once every two years. In the baseline scenario, we use data from the Growing Up in Ireland (GUI) survey, which records the proportion of children who visited a dentist at least once in the previous two years. The data show that 83.1 per cent of children aged nine years of age, and 83.9 per cent of children aged 13 years of age had visited a dentist at least once over the past two years. ${ }^{27}$ We therefore assume that the eligible population is adjusted downwards

27 The relevant question (asked of the child's primary caregiver, usually the mother) is 'Which of the following best describes how regularly the Study Child visits the dentist? Responses are 'at least once a year', 'Once every two years', 'Once every three years', 'Only when there is a problem' and 'Never/almost never'. We aggregate the proportions visiting 'at least once a year' and 'once every two years' to derive an estimate of the proportion of children who may be expected to visit a dentist within a two-year period. For children aged 0-1, 2-5 and 6-11, we use 
to account for this average take-up. However, the GUI data refer to visiting rates which are self-reported, and which apply in the current financing model (i.e. with most individuals paying the full cost out-of-pocket). In sensitivity analyses (detailed below), we assess the implications for expenditure of varying the estimated take-up to consider alternative estimates of take-up from administrative data from the UK NHS.

Data on the usage frequency of each service (e.g. one oral assessment during the age range 0-2 years) were provided by the Department of Health.

\subsection{SENSITIVITY ANALYSES}

We then run a number of separate additional analyses to test the sensitivity of our estimates of annual expenditure to variations in our underlying assumptions. We run nine sensitivity analyses as follows:

1. Assuming that the oral health assessment at age 0-2 may be carried out by another professional such as a dental hygienist or nurse, at a lower unit cost. We assume an alternative price per unit of $€ 25$ for this service; ${ }^{28}$

2. Assuming alternative take-up of services. The estimates of alternative take-up we use are derived from data from NHS Scotland, which documents that the proportion of children aged 0-17 who had visited a dentist in the previous two years ranged from 81 per cent (for children aged 13-17) to 98 per cent (for children aged $0-2){ }^{29}$

3. Assuming that fluoride therapy will also be made available to children aged 2$5 ;^{30}$

4. Assuming that fluoride therapy will be made available to all children aged 2-5 and 6-11, regardless of their residence in a fluoridated/non-fluoridated area;

5. Assuming one fissure sealant treatment in the age range 6-11, and one fissure sealant treatment in the age range 12-15, rather than two in the age

the GUI visiting rate for nine-year-olds, while for children aged 12-15, we use the GUI visiting rate for 13-year-olds. GUI questionnaires are available from: http://www.esri.ie/growing-up-in-ireland/questionnaires [last accessed 7 September 2018].

28 The alternative price per unit for an oral health assessment at age 0-2 was provided by the Department of Health (personal communication, 27 November 2017).

29 Data from NHS Scotland for 2016 indicate that 98.3 per cent of children aged 0-2, 89.2 per cent of children aged 3-5, 84.4 per cent of children aged 6-12 and 80.6 per cent of children aged 13-17 had visited a dentist in the previous two years (NHS, 2016).

30 Fluoride is a mineral that prevents tooth decay. Fluoride can be administered in different ways, either topically (toothpastes, mouth rinses, varnishes, gels) or systemically (fluoride supplements, fluoridated water, salt). Topical fluorides have been shown to be highly effective and the use of fluoride-containing toothpastes is now almost universal. When daily tooth-brushing with a fluoridated toothpaste is not carried out or when the caries-risk is increased, additional sources of fluoride can be recommended (Tubert-Jeannin et al., 2011). However, the evidence for the appropriateness of fluoride therapy for young children (less than six years) is inconclusive (Centers for Disease Control and Prevention, 2001, Tubert-Jeannin et al., 2011, Wong et al., 2010). 
range 6-11. This alternative scenario reflects the high degree of variation in the eruption dates for first and second permanent molars, meaning that greater flexibility in assessment and treatment ages for fissure sealants is recommended; ${ }^{31}$

6. Assuming that a subset of children aged $2+$ years will require emergency treatment in the form of one extraction per age range; ${ }^{32}$

7. Assuming that all children aged 2-5 will require two emergency prescriptions during that age range;

8. Assuming that children should receive an assessment/examination once per annum;

9. Using an alternative definition of DMFT to estimate potential need for fillings and emergency extractions. ${ }^{33}$

\subsection{RESULTS}

We present first the results for the baseline scenario for the package of services set out in Table 5.2 (results presented in Table 5.4). Annual expenditure for the provision of a primary dental care service to all children under the age of 16 years of age is estimated to be $€ 26.5$ million. For each age range, the oral examination accounts for the majority of the estimated expenditure, reflecting the recommendation that all children receive an oral examination approximately every two years.

Dental sealants were introduced in the 1960s to help prevent dental caries, mainly in the pits and fissures of occlusal (biting) tooth surfaces. Sealants act to prevent bacteria growth that can lead to dental decay. A recent Cochrane Systematic Review found that resin-based sealants applied on the occlusal surfaces of permanent molars are effective for preventing caries in children and adolescents (Ahovuo-Saloranta et al., 2017). However, there is considerable variability in the ages at which first and second permanent molars erupt. For example, a 2010 guidance study on pit and fissure sealants cites evidence from a number of European studies which show that the age range for permanent molar emergence is wide: from age five to eight for first permanent molars and from age nine to 15 for second permanent molars (Irish Oral Health Services Guideline Initiative, 2010). Data from the National Health Examination and Nutrition Survey in the US also show wide variation in eruption ages, particularly for second permanent molars. They also find that eruption ages differ by sex and race (Pahel et al., 2017). To reflect this variability, in our alternative scenario, we assume that children aged 6-11 will avail of one fissure sealant treatment, while the remaining treatment will be carried out in the age range 12-15. The baseline scenario assumes that both fissure sealant treatments will be carried out in the age range 6-11.

32 We use data from the Fluoride and Caring for Children's Teeth (FACCT) study of 5- and 12-year-olds in Dublin, Cork and Kerry in 2013/2014 on the number of DMFT to calculate the proportion of children at ages 2-5, 6-11 and 12-15 who may be expected to need an extraction. For example, for children aged 5, FACCT shows that there is an average of 1 DMFT, which equates to approximately 5 per cent of their total teeth at that age; we therefore assume that 5 per cent of children aged 2-5 will potentially need an extraction. The proportions for children aged 6-11 and 12-15 are estimated to be 3.75 per cent, and 2.5 per cent, respectively.

33 In general in Ireland, the convention is to use $\mathrm{D}_{3 \mathrm{c}} \mathrm{MFT}$ (i.e. without visual caries), while the convention in the UK is to use $D_{3 v c}$ MFT (i.e. with visual caries) (Whelton et al., 2006). This sensitivity analysis considers the implications of assuming higher cavity rates, by using data on $\mathrm{D}_{3 \mathrm{vc}} \mathrm{MFT}$ instead of data on $\mathrm{D}_{3 c} \mathrm{MFT}$ (which is used in the baseline scenario). 
TABLE 5.4 BASELINE SCENARIO (CHILDREN)

\begin{tabular}{|c|l|c|}
\hline \multicolumn{1}{|c|}{ Age Group } & \multicolumn{1}{|c|}{ Dental Treatment } & Emillion \\
\hline $\mathbf{0 - 1}$ & Assessment & 1.8 \\
\hline $\mathbf{2 - 5}$ & Examination & 3.8 \\
& Filling & 1.8 \\
\hline \multirow{2}{*}{$\mathbf{6 - 1 1}$} & Examination & 5.5 \\
& Filling & 1.9 \\
\hline \multirow{2}{*}{$\mathbf{1 2 - 1 5}$} & Fissure sealants & 5.6 \\
\hline Total & Fluoride therapy & 0.6 \\
\hline
\end{tabular}

Source: Author's analysis.

Note: $\quad$ Underlying assumptions: Price per unit, eligible population, take-up and usage frequency as per Table 5.3.

The results of the sensitivity analyses are presented in Table 5.5. These estimates are most sensitive to alternative assumptions about the frequency of assessments/examinations, and the relevant population for fluoride therapy. Assuming that all children should receive an assessment/examination once per annum raises expenditure substantially, to $€ 41.1$ million per annum. Allowing all children aged 2-5 and 6-11 to avail of the recommended course of fluoride therapy, regardless of their residence in a fluoridated/non-fluoridated area increases annual expenditure to $€ 32.3$ million. Two scenarios result in reduced expenditure. Reducing the price per unit for dental assessments at age 0-1 reduces expenditure to $€ 26.0$ million, while changing the eligible age group for fissure sealants reduces expenditure to $€ 26.3$ million (as there are fewer children aged 12-15 than aged 6-11).

The remaining scenarios have more limited impacts on annual expenditure. For example, changing the estimated take-up rates to reflect those currently observed among Scottish children increases expenditure to $€ 27.2$ million. Assuming that all 2- to 5-year-olds living in non-fluoridated areas can avail of fluoride therapy (in addition to all 6- to 11-year-olds living in non-fluoridated areas) increases the estimated annual cost of the primary care programme to $€ 26.9$ million. Providing for one emergency extraction for at-risk children increases expenditure marginally (to $€ 26.7$ million), reflecting low rates of DMFT in Irish children at present. 


\begin{tabular}{|c|c|c|c|c|c|c|c|c|c|c|}
\hline & & \multicolumn{9}{|c|}{ Emillion } \\
\hline $\begin{array}{l}\text { Age } \\
\text { Group }\end{array}$ & Dental Treatment & (1) & (2) & (3) & (4) & (5) & (6) & (7) & (8) & (9) \\
\hline $0-1$ & Assessment & 1.4 & 2.1 & 1.8 & 1.8 & 1.8 & 1.8 & 1.8 & 3.6 & 1.8 \\
\hline \multirow{5}{*}{$2-5$} & Examination & 3.8 & 4.1 & 3.8 & 3.8 & 3.8 & 3.8 & 3.8 & 7.7 & 3.8 \\
\hline & Emergency extraction & - & - & - & - & - & 0.1 & - & - & 0.1 \\
\hline & Emergency prescription & - & - & - & - & - & - & 2.6 & - & - \\
\hline & Filling & 1.8 & 1.9 & 1.8 & 1.8 & 1.8 & 1.8 & 1.8 & 1.8 & 2.3 \\
\hline & Fluoride therapy & - & - & 0.4 & 2.6 & - & - & - & - & - \\
\hline \multirow{5}{*}{ 6-11 } & Examination & 5.5 & 5.6 & 5.5 & 5.5 & 5.5 & 5.5 & 5.5 & 11.1 & 5.5 \\
\hline & Emergency extraction & - & - & - & - & - & 0.1 & - & - & 0.1 \\
\hline & Filling & 1.9 & 2.0 & 1.9 & 1.9 & 1.9 & 1.9 & 1.9 & 1.9 & 2.4 \\
\hline & Fissure sealants & 5.6 & 5.7 & 5.6 & 5.6 & 2.8 & 5.6 & 5.6 & 5.6 & 5.6 \\
\hline & Fluoride therapy & 0.6 & 0.6 & 0.6 & 3.8 & 0.6 & 0.6 & 0.6 & 0.6 & 0.6 \\
\hline \multirow{4}{*}{$12-15$} & Examination & 3.4 & 3.3 & 3.4 & 3.4 & 3.4 & 3.4 & 3.4 & 6.8 & 3.4 \\
\hline & Emergency extraction & - & - & - & - & - & 0.0 & - & - & 0.1 \\
\hline & Filling & 2.0 & 1.9 & 2.0 & 2.0 & 2.0 & 2.0 & 2.0 & 2.0 & 2.4 \\
\hline & Fissure sealants & - & - & - & - & 2.6 & - & - & - & - \\
\hline Total & & 26.0 & 27.2 & 26.9 & 32.3 & 26.3 & 26.7 & 29.1 & 41.1 & 28.1 \\
\hline
\end{tabular}

Source: Author's analysis.

Note: Alternative scenario assumptions:

1. Lower price $(€ 25)$ for the delivery of dental assessment to children aged 0-1 years of age.

2. Alternative take-up rates among the eligible population, using data from NHS Scotland (NHS, 2016).

3. Including fluoride therapy for children aged 2-5.

4. Including fluoride therapy for all children aged 2-5 and 6-11, including those in fluoridated areas.

5. One fissure sealant treatment to be provided at age 6-11 and one at age 12-15.

6. Including additional treatment of emergency extractions for a subset of children potentially in need of an extraction.

7. Including emergency prescriptions for children aged 2-5.

8. Annual assessment/examination for all children.

9. Using alternative definition of DMFT (i.e. $D_{3 v c}$ MFT, including visual cavities) to assess potential need for fillings and emergency extractions.

Combining the data in Tables 5.3 and 5.4, it is possible to generate indicative estimates of the cost of the treatment packages for different age ranges. The results of this exercise are presented in Table 5.6, and illustrate that, for example, the cost of the provision of a primary dental healthcare package to a 2- to 5-yearold with no decay in a non-fluoridated area would be $€ 66$ (for that four-year period). Reflecting the greater range of services recommended for children in the age range $6-11$, the estimated cost of a package of primary dental healthcare services for a child aged 6-11 with no decay in a non-fluoridated area would be $€ 264.07$ (for that six-year period). 
TABLE 5.6 APPROXIMATE PACKAGE PAYMENT BY AGE GROUP (BASELINE SCENARIO, CHILDREN)

\begin{tabular}{|l|c|c|c|c|}
\hline & \multicolumn{2}{|c|}{ Fluoridated Areas } & \multicolumn{2}{c|}{ Non-Fluoridated Areas } \\
\hline Age Group & $\begin{array}{c}\text { DMFT=0 } \\
€\end{array}$ & $\begin{array}{c}\text { DMFT>0 } \\
\text { DMFT=0 } \\
€\end{array}$ & $\begin{array}{c}\text { DMFT>0 } \\
€\end{array}$ \\
\hline $0-1$ & 33.00 & 33.00 & 33.00 & 33.00 \\
\hline $2-5$ & 66.00 & 169.76 & 66.00 & 169.76 \\
\hline $6-11$ & 199.12 & 302.88 & 264.07 & 367.83 \\
\hline $12-15$ & 66.00 & 169.76 & 66.00 & 169.76 \\
\hline
\end{tabular}

Source: Author's analysis.

Note: $\quad$ Price per unit, eligible population, take-up and usage frequency as per the baseline scenario (see Table 5.3 for relevant services). 


\section{CHAPTER 6}

\section{Summary and policy implications}

\subsection{INTRODUCTION}

This report detailed the results of an analysis of the potential cost implications of proposed changes to aspects of the model of delivery of publicly-financed dental services in Ireland, as set out in the new National Oral Health Policy (Department of Health, 2018b). The analysis was carried out under the joint research programme between the ESRI and the Department of Health. The cost analysis was conducted to assist the Department of Health in assessing the feasibility and affordability of the recommendations outlined in the new policy and in ascertaining the parameters which are likely to have the largest impact on cost. While a number of alternative scenarios have been examined and a number of assumptions have been made to facilitate this analysis, this analysis was not an end in itself and it was not intended to draw conclusions about the anticipated final cost of the publicly-funded schemes of the new National Oral Health Policy.

Three research questions were examined in this report:

1. What is the national and international evidence on the effects of different methods of provider payment on dental healthcare provision and outcomes?

2. What is the estimated cost per annum of providing alternative packages of primary dental healthcare services to all adult medical cardholders?

3. What is the estimated cost per annum of providing alternative packages of primary dental healthcare services to all children aged 0-16?

\subsection{SUMMARY}

\subsubsection{Provider payment methods}

Taking the first question, in order to assess the most appropriate payment method for the reimbursement of dentists for services provided in the public system, the report begins by reviewing briefly the theoretical and empirical literature on provider payment methods in primary care, and dentistry in particular. The review highlights that the optimal mix between the main methods of provider payment - namely capitation, FFS and salary - is still open to question. No one payment method can achieve all desired policy objectives as there are trade-offs involved in favouring one method over another. The choice of payment method in part depends on the importance of different policy priorities such as access, efficiency and quality. 
New payment initiatives such as P4P are being implemented in many countries, but their success is dependent on the accuracy with which outcomes can be measured. In particular, the difficulty in measuring clinical outcomes in dentistry has been highlighted (Grytten, 2017). In an effort to overcome some of the limitations of capitation or similar prospective payment methods, many countries are now experimenting with bundled payment initiatives, initially largely in acute care settings. As these initiatives are still in the development or pilot phase in many countries, they have not yet been subject to rigorous evaluations of their impacts on efficiency, access, quality and patient health outcomes.

\subsubsection{Costing alternative preventive dental healthcare packages}

The assessment of the expenditure implications of alternative preventive dental healthcare packages resulted in a range of annual expenditure figures for both adult medical cardholders and children. For example, the annual cost of a package of care under the baseline scenario for adult medical cardholders is estimated to be $€ 23.0$ million, with estimates under alternative scenarios ranging from $€ 6.9$ million to $€ 42.8$ million. Annual expenditure for the provision of a primary dental care service to all children under the age of 16 years of age is estimated to be $€ 26.5$ million, with estimates under alternative scenarios ranging from $€ 26.0$ million to $€ 41.1$ million.

The range of estimates presented in Sections 4 and 5 is designed to assist policymakers tasked with designing an alternative package of dental healthcare services, and associated provider payment structure, for adult medical cardholders and children respectively. However, it is important to highlight a number of caveats in interpreting these results. First, these are estimates of annual public expenditure for alternative packages of largely preventive care services only. For simplicity, and in order to isolate the effect of various policy parameters, we do not consider possible interactions between the different sensitivity analyses. In addition, the estimated cost of additional packages of services to cover medical interventions such as extractions, endodontic treatment, etc., and complex interventions such as crowns, bridges, etc. is not considered as part of the current study.

Second, the analysis does not consider the capacity (i.e. staff, equipment, etc.) required to deliver alternative models of preventive dental healthcare to these two key population groups. In particular, the proposal to change the delivery setting for the provision of services to children from community dentists employed by the PDS to independent practitioners in the community represents a major change in how dental healthcare services for children will be delivered. The potential impacts on independent dental practice (or wider implications in terms of workforce planning, training, etc.) are not being considered here. 
Third, the estimates are based on data for 2015. It is therefore a static analysis, assuming no behavioural or organisational change by individuals or providers as a consequence of a possible change in the package of primary dental healthcare services available, and associated provider payment methods. For example, for the analysis of children, we do not model the potential impact of improved oral health as a result of the alternative primary care package on future oral health needs, which may impact the frequency with which future cohorts of children may require particular services (e.g. fillings). In addition, we do not consider the potential impact of providers (dentists) responding to the new model of care for both adult medical cardholders and children, and associated provider payment methods, by changing their behaviour. Indeed, Woods et al. (2010) demonstrated that changes to the fee reimbursed for fillings and extractions under the DTSS in 1999 led to significant changes in behaviour on the part of dentists.

Fourth, we assume that unit costs of providing the various services to adult medical cardholders and children in independent practice are equivalent to the existing FFS reimbursement levels for these or equivalent services as set out in Tables 4.3 and 5.3. Ideally, the costing exercise would generate data on the most appropriate payment level for different treatments using data from a number of sources (e.g. provider unit costs, patient needs, cost effectiveness of interventions, etc.). In the absence of the availability of all these data in the Irish context at present, $^{34}$ the current costing exercise has adopted a simplified approach, using data on the price of each service (proxied by the current FFS price).

Finally, how do these estimates compare with current expenditure on publiclyfinanced dental services for adult medical cardholders and children? Focusing on the case of adult medical cardholders, the baseline scenario results in estimated annual expenditures of $€ 23.0$ million ( $€ 42.3$ million if an additional provision for one filling per annum per eligible individual is allowed). In comparison, in 2015, expenditure on 'above-the-line' treatments under the current DTSS totalled $€ 48.1$ million and expenditure on 'below-the-line' treatments totalled $€ 18.3$ million. A direct comparison between the estimated annual expenditure on an alternative package of preventive dental healthcare services with existing expenditure on 'above-the-line' treatments is not appropriate. A similar costing exercise would need to be undertaken to assess the expenditure implications of providing additional packages covering more complex interventions such as crowns, endodontics etc. under the DTSS in order to predict total public expenditure on dental healthcare services for adult medical cardholders.

34 The current phase of the development of the Hippocrates model of healthcare demand and expenditure is gathering data, where available, on unit costs of care across a variety of care settings in Ireland (Wren et al., 2017). 
Nonetheless, the availability of a range of estimates provides guidance to policymakers on the choices available in designing an alternative package of preventive dental healthcare services (in terms of included services, price, eligible population and usage frequency of each service).

\subsection{POLICY IMPLICATIONS}

\subsubsection{Provider payment methods}

In drawing implications for policy from the literature review of provider payment methods, a number of issues are relevant. First, it is important to note that the extent to which providers are influenced by the way in which they are paid is dependent on the strength of the different factors motivating their behaviour (e.g. self-interest, patients' interest, medical ethics, etc.). ${ }^{35}$ In the Irish context for example, the fact that dentists providing publicly-financed services also operate in the private sector, providing services to non-medical cardholders on a FFS basis needs to be considered. Previous research has highlighted that the strength or otherwise of alternative provider payment methods depends on the extent to which providers are relying on this source of payment as their main source of income (Brocklehurst et al., 2013). In Ireland in 2013, it was estimated that just 14 per cent of total expenditure on dental healthcare services (including orthodontics) was accounted for by the public sector (Wren et al., 2015). In addition, where providers face different payment methods for the provision of the same services to different population groups, this can generate an inconsistency in the incentives facing providers across different population groups which may lead to inequities in treatment (Brick et al., 2012). Under the National Oral Health Policy, dentists will (continue to) face different payment methods for different services and different population groups, and the full implications of these different payment methods and resulting incentives will need to be monitored carefully in the implementation of the new policy.

While it is difficult to predict how dentists will respond to the changes in reimbursement proposed under the National Oral Health Policy, to the extent that the mix of services reimbursable under the DTSS will now change, this may be expected to result in differences in the mix of services provided by dentists. As noted, changes in reimbursement under the DTSS in 1999 led to significant changes in behaviour on the part of dentists. In addition, for the provision of services to adult medical cardholders, the movement from FFS to prospective

35 A large amount of experimental evidence from psychology shows that when an activity is driven by intrinsic motivation, such as professionalism, or pride in the quality of one's work, then adding a financial motive might undermine, or 'crowd out', intrinsic motivation. This reduces the incentive effect from monetary rewards. In the worst case, crowding out may lead to less activity rather than more. This would be the case if intrinsic motivation is high and the crowding-out effect is strong (Grytten, 2017). 
payment will change provider incentives, although the full impact of the change is difficult to predict without also considering how patients will react.

Indeed, the incentives built in to different provider payment methods may also be offset partly or fully by incentives on the demand side for individuals to use dentistry services (Brick et al., 2010; 2012). For example, for those without Medical Cards in Ireland, patient and provider financial incentives conflict in terms of the utilisation of dental care (patients pay the full cost out-of-pocket, while providers receive a FFS for each visit). This problem may be a particular issue with dentistry where the bulk of service delivery, in terms of volume of activity, is based on the regular attendance of asymptomatic patients. Therefore, characteristics of patients such as expectations and health literacy may be relatively more important in encouraging uptake of dental services (Brocklehurst et al., 2013). In addition, in the field of prevention, it has been noted that informing and incentivising patients may be as important as incentivising healthcare providers to provide screening or immunisation services (Cashin et al., 2012). The interaction with incentives facing alternative providers may also be important. Taking the example of primary care, it has been noted that combining capitation payments for one set of providers (e.g. GPs) with FFS payments for another set of providers (e.g. specialists) runs the risk of excess referrals and 'dumping' of patients (Saltman et al., 2005). In this context, it is also increasingly accepted that payment mechanisms need to be supported by non-price mechanisms, such as the setting and monitoring of clinical protocols (Robinson, 2001; Birch, 2015). Furthermore, the administrative burden on patients, providers and funders associated with complex reimbursement and co-payment structures should not be underestimated, as well as the implications for transparency (Robinson, 2001).

Finally, to the extent that the costs incurred result not merely from the effort of the provider but also from factors outside the provider's control (e.g. macroeconomic conditions, patient behaviour, etc.), prospective payment methods such as capitation or bundling exposes the provider to new financial risks. Prospective payment rates can be adjusted for the expected severity of the patient's condition (e.g. using age/sex adjustment of payment rates), but these adjustments may only account for a modest proportion of the variation in costs. The design challenge facing the payer is further complicated in contexts where the desired behaviour of the provider comprises a variety of different tasks, some of which can be more easily measured than others. Attempts to link payment to particular tasks may therefore lead to an overinvestment in the provider's time in those tasks that are explicitly measured and rewarded, and an underinvestment elsewhere (Robinson, 2001). This issue has been highlighted as a particular problem for dentistry, where there is an absence of agreed clinical indicators of the severity of dental diseases (Grytten, 2017). 


\subsubsection{Costing alternative preventive dental healthcare packages}

The alternative preventive dental healthcare packages examined in this report are designed to illustrate the choices facing policymakers in the context of the development of a new national oral health policy. The various scenarios illustrate the impact of alternative choices around the recommended services, price, eligible population and recommended usage frequency of preventive dental healthcare services on estimated public expenditure. Factors not directly under the control of policymakers, such as take-up of services, are also considered. Estimates of the cost of the alternative preventive dental healthcare packages for particular population groups (presented in Tables 4.6 and 5.6) also illustrate the impact of these choices on expenditure levels under the alternative packages. As noted however, the analysis is a static one, assuming no behavioural or organisational change by individuals or providers as a consequence of a possible change in the package of preventive dental healthcare services available, and associated provider payment methods. Further modelling work would be required to assess the implications of the provision of alternative packages of preventive dental healthcare services to adult medical cardholders and children for future oral health needs, and how this may influence future expenditure, not only on preventive dental healthcare services, but also on medical and complex dental interventions (such as extractions, endodontic treatment, crowns, bridges, etc.).

The range of estimates can be used by policymakers to assess the implications of changes to policy parameters such as unit price per service, population coverage and recommended usage frequency. For example, it is clear that changing the eligible population for particular services can lead to considerable differences in annual expenditure (e.g. allowing all children aged 2-11 to avail of fluoride therapy, regardless of whether their area is fluoridated). The costing method employed in this report may also be used to assess the implications of other proposals that may be forthcoming from the recent Sláintecare report which recommended a universal comprehensive package of dental healthcare services (Houses of the Oireachtas, 2017; 67). As noted, the developing Hippocrates model of healthcare demand and expenditure ${ }^{36}$ will, in time, be able to incorporate analyses such as these, and to consider the implications of behavioural change.

Finally, a consistent theme running through the empirical literature on provider payment was the lack of appropriate study designs with which to evaluate the causal impact of provider payment on health policy objectives (e.g. cost control, access, activity, patient health outcomes, etc.) (Flodgren et al., 2011; Scott et al., 2011; Nolan et al., 2011). In contemplating a policy change, it is important to collect data that would facilitate a rigorous evaluation of the policy change. In the 
absence of a randomised control trial (RCT), ${ }^{37}$ this could involve the collection of data before and after the policy change on both a treatment group (e.g. those visiting dentists reimbursed under an alternative preventive healthcare contract) and a control group (e.g. those visiting dentists reimbursed under the existing FFS contract), thereby allowing the analyst to separate out the effect of the policy change from other secular changes over time that were common to both the treatment and control groups. In any case, introducing an alternative preventive dental healthcare package offers opportunities for enhanced data collection that can also facilitate the achievement of other objectives such as public health surveillance. Currently there is a requirement for dentists participating in the DTSS to provide additional information on oral health when claiming reimbursement under the DTSS (for example, after prophylaxis dentists were required to provide an assessment of periodontal health) (PCRS, 2006); such a requirement could be extended to other indicators of oral health as part of an alternative contract for the delivery of preventive oral healthcare services. 



\section{References}

Agency For Healthcare Research and Quality (2011). 'Bundled Payment: Effects on Health Care Spending and Quality', Closing the Quality Gap: Revisiting the State of the Science, Washington, Agency for Healthcare Research and Quality.

Ahovuo-Saloranta, A., H. Forss, T. Walsh, A. Nordblad, M. Mäkelä and H. Worthington (2017). 'Pit and fissure sealants for preventing dental decay in permanent teeth', Cochrane Database of Systematic Reviews.

Altman, S. (2012). 'The Lessons Of Medicare's Prospective Payment System Show That The Bundled Payment Program Faces Challenges', Health Affairs, 31, 19231930.

Birch, S. (2015). 'Paying for prevention in clinical practice: Aligning provider remuneration with system objectives', BMC Oral Health, 15, S7-S7.

Blomqvist, A. (2011). 'Public-Sector Health Care Financing', in Glied, S. and P. Smith (Eds.) The Oxford Handbook of Health Economics, Oxford, Oxford University Press.

Brick, A., A. Nolan, J. O'Reilly and S. Smith (2010). 'Resource Allocation, Financing and Sustainability in Health Care', Evidence for the Expert Group on Resource Allocation and Financing in the Health Sector, Dublin, Department of Health and Children and Economic and Social Research Institute.

Brick, A., A. Nolan, J. O'Reilly and S. Smith (2012). 'Conflicting Financial Incentives in the Irish Health-Care System', The Economic and Social Review, 43, 273-301.

Brocklehurst, P., J. Price, A.-M. Glenny, M. Tickle, S. Birch, E. Mertz and J. Grytten (2013). 'The effect of different methods of remuneration on the behaviour of primary care dentists', Cochrane Database of Systematic Reviews.

Casemix Ireland (2012). 'Case Mix Unit Review of Prospective Funding', Dublin, HSE.

Cashin, C., Y. Chi, P. Smith, M. Borowitz and S. Thomson (2012). 'Paying for Performance in Healthcare', Implications for Health System Performance and Accountability, European Observatory on Health Systems and Policies.

Cassidy, A. (2015). 'Bundled Payments for Care Improvement Initiative', Health Affairs, November.

Centers For Disease Control And Prevention (2001). Recommendations for Using Fluoride to Prevent and Control Dental Caries in the United States, Atlanta, Centers for Disease Control and Prevention.

Chalkley, M. and C. Tilley (2006). 'Treatment intensity and provider remuneration: dentists in the British National Health Service', Health Economics, 15, 933-946.

Chalkley, M., C. Tilley, L. Young, D. Bonetti and J. Clarkson (2010). 'Incentives for Dentists in Public Service: Evidence from a Natural Experiment', Journal of Public Administration Research and Theory, 20, i207-i223.

Charleston, A., A. Davies and J. Dixon (2012). Reforming Payment for Health Care in Europe to Achieve Better Value for Money, Oxford, Nuffield Trust. 
Christianson, J. and D. Conrad (2011). 'Provider Payment and Incentives', in Glied, S. and P. Smith (Eds.) The Oxford Handbook of Health Economics, Oxford, Oxford University Press.

Clarkson, J., S. Turner, J. Grimshaw, C. Ramsay, M. Johnston and A. Scott (2008). 'Changing Clinicians' Behavior: A Randomized Controlled Trial of Fees and Education', Journal of Dental Research, 87, 640-644.

Conrad, D. (2015). 'The Theory of Value-Based Payment Incentives and Their Application to Health Care', Health Services Research, 50, 2057-2089.

Cornejo-Ovalle, M., R. Brignardello-Petersen and G. Pérez (2015). 'Pay-for-performance and efficiency in primary oral health care practices in Chile', Revista Clínica de Periodoncia, Implantología y Rehabilitación Oral, 8, 60-66.

Coventry, P., P. Holloway, M. Lennon, A. Mellor and H. Worthington (1989). 'A trial of a capitation system of payment for the treatment of children in the General Dental Service', Community Dental Health, 6, 1-63.

CSO (2017). 'System of Health Accounts', Ireland's System of Health Accounts, Annual Results 2015. Dublin, CSO.

De Bakker, D., J. Struijs, C. Baan, J. Raams, J. De Wildt, H. Vrijhoef and F. Schut (2012). 'Early Results From Adoption Of Bundled Payment For Diabetes Care In The Netherlands Show Improvement In Care Coordination', Health Affairs, 31, 426433.

Department of Health (1994). The Dental Health Action Plan, Dublin, Department of Health.

Department of Health (1999). Expenditure Review of the Dental Treatment Services Scheme (DTSS), Dublin, Department of Health.

Department of Health (2011). Comprehensive Review of Expenditure September 2011, Dublin, Department of Health.

Department of Health (2016). Briefing for Minister for Health - May 2016, Dublin, Department of Health.

Department of Health (2018a). Health in Ireland Key Trends 2017, Dublin, Department of Health.

Department of Health (2018b). National Oral Health Policy, Dublin, Department of Health.

Department of Social Protection (2016). Statistical Information on Social Welfare Services, Dublin, Department of Social Protection.

Devaux, M. and M. De Looper (2012). 'Income-Related Inequalities in Health Service Utilisation in 19 OECD Countries, 2008-2009', OECD Health Working Papers No. 58. Paris, OECD.

Ellis, R. (1998). 'Creaming, skimping and dumping: provider competition on the intensive and extensive margins', Journal of Health Economics, 17, 537-555.

Flodgren, G., M. Eccles, S. Shepperd, A. Scott, E. Parmelli and F. Beyer (2011). 'An overview of reviews evaluating the effectiveness of financial incentives in 
changing healthcare professional behaviours and patient outcomes', Cochrane Database of Systematic Reviews.

Friedberg, M., P. Chen, C. White, O. Jung, L. Raaen, S. Hirshman, E. Hoch, C. Stevens, P. Ginsburg, L. Casalino, M. Tutty, C. Vargo and L. Lipinski (2015). Effects of Health Care Payment Models on Physician Practice in the United States, Santa Monica, RAND.

Giuffrida, A., T. Gosden, F. Forland, I. Kristiansen, M. Sergison, B. Leese, L. Pedersen and M. Sutton (1999). 'Target payments in primary care: effects on professional practice and health care outcomes', Cochrane Database of Systematic Reviews, 4, 1-12.

Gosden, T., F. Forland, I. Kristiansen, M. Sutton, B. Leese, A. Giuffrida, M. Sergison and L. Pedersen (2000). 'Capitation, salary, fee-for-service and mixed systems of payment: effects on the behaviour of primary care physicians', Cochrane Database of Systematic Reviews.

Gosden, T., F. Forland, I. Kristiansen, M. Sutton, B. Leese, A. Giuffrida, M. Sergison and L. Pedersen (2001). 'Impact of payment method on behaviour of primary care physicians: a systematic review', Journal of Health Services Research \& Policy, 6, 44-55.

Government of Ireland (2009). 'Health Professionals (Reductions of Payments to Registered Dentists) Regulations 2009', Statutory Instrument No. 171 of 2009. Dublin, The Stationery Office.

Government of Ireland (2011). 'Health Professionals (Reductions of Payments to Registered Dentists) Regulations 2011', Statutory Instrument No. 135 of 2011. Dublin, The Stationery Office.

Government of Ireland (2012). 'Health Professionals (Reductions of Payments to Registered Dentists) Regulations 2012', Statutory Instrument No. 548 of 2012. Dublin, The Stationery Office.

Gress, S., D. Delnoij and P. Groenewegen (2006). 'Managing Primary Care Behaviour Through Payment Systems and Financial Incentives', in Saltman, R., A. Rico and W. Beorma (Eds.), Primary Care in the Driver's Seat. Geneva, WHO Regional Office for Europe.

Grytten, J. (2017). 'Payment systems and incentives in dentistry', Community Dentistry and Oral Epidemiology, 45, 1-11.

Grytten, J., D. Holst and I. Skau (2009). 'Incentives and remuneration systems in dental services', International Journal of Health Care Finance and Economics, 9, 259278.

Grytten, J., D. Holst and I. Skau (2013). 'Per capita remuneration of dentists and the quality of dental services', Community Dentistry and Oral Epidemiology, 41, 395-400.

Health Insurance Authority (2018). Quarterly Newsletter. May 2018, Dublin, Health Insurance Authority.

Hennig-Schmidt, H., R. Selten and D. Wiesen (2011). 'How payment systems affect physicians' provision behaviour - An experimental investigation', Journal of Health Economics, 30, 637-646. 
Hill, H., S. Birch, M. Tickle, R. McDonald, M. Donaldson, D. O'Carolan and P. Brocklehurst (2017). 'Does capitation affect the delivery of oral healthcare and access to services? Evidence from a pilot contact in Northern Ireland', BMC Health Services Research, 17, 175.

Houses of the Oireachtas (2017). Committee on the Future of Healthcare Sláintecare Report, Dublin, Houses of the Oireachtas.

HSE (2015). National Model of Care for Trauma and Orthopaedic Surgery, Dublin, HSE.

HSE (2018). Health Service Employment. January 2017. Dublin, HSE.

Irish Oral Health Services Guideline Initiative (2010). Pit and Fissure Sealants: Evidencebased guidance on the use of sealants for the prevention and management of pit and fissure caries, Cork, University College Cork.

Jegers, M., K. Kesteloot, D. De Graeve and W. Gilles (2002). 'A typology for provider payment systems in health care', Health Policy, 60, 255-273.

Kristiansen, I. and G. Mooney (1993). 'The general practitioner's use of time: Is it influenced by the remuneration system?' Social Science \& Medicine, 37, 393399.

Listl, S. and M. Chalkley (2014). 'Provider payment bares teeth: Dentist reimbursement and the use of check-up examinations', Social Science \& Medicine, 111, 110116.

Newhouse, J. and S. Normand (2017). 'Health Policy Trials', New England Journal of Medicine, 376, 2160-2167.

NHS (2016). Dental Statistics - NHS Registration and Participation, Edinburgh, NHS.

Nolan, A., J. O'Reilly, S. Smith and A. Brick (2011). 'The Potential Role of Pay-forPerformance in Irish Health Care', ESRI Renewal Series Paper No. 4. Dublin, Economic and Social Research Institute.

O'Sullivan, V. and B. O'Connell (2015). 'Water fluoridation, dentition status and bone health of older people in Ireland', Community Dentistry and Oral Epidemiology, $43,58-67$.

OECD (2018). State of Health in the EU Ireland Country Health Profile 2017. Paris, OECD.

Ogundeji, Y., J. Bland and T. Sheldon (2016). 'The effectiveness of payment for performance in health care: A meta-analysis and exploration of variation in outcomes', Health Policy, 120, 1141-1150.

Oral Health Policy Academic Reference Group (2016). 'Interim Report'. Unpublished interim report of the Department of Health Oral Health Policy Academic Reference Group.

Pahel, B., W. Vann, K. Divaris and R. Rozier (2017). 'A Contemporary Examination of First and Second Permanent Molar Emergence', Journal of Dental Research, 96, 1115-1121.

PCRS (2006). Information and Administrative Arrangements for Dentists. Dublin, HSE.

PCRS (2016a). DTSS Expenditure Report (excluding Health Amendment Act claims) for December 2015. Dublin, HSE. 
PCRS (2016b). Statistical Analysis of Claims and Payments 2015. Dublin, HSE.

PCRS (2018). Information and Administrative Arrangements for Dentists. Dublin, HSE.

Porter, M. and R. Kaplan (2016). 'How to Pay for Health Care', Harvard Business Review, July-August.

Robinson, J. (2001). 'Theory and Practice in the Design of Physician Payment Incentives', Milbank Quarterly, 79, 149-177.

Roland, M. and B. Guthrie (2016). 'Quality and Outcomes Framework: what have we learnt?', British Medical Journal, 354.

Rosenthal, M. (1999). 'Risk sharing in managed behavioral health care', Health Affairs, 18, 204-213.

Rosenthal, M. (2000). 'Risk sharing and the supply of mental health services', Journal of Health Economics, 19, 1047-1065.

Saltman, R., A. Rica and W. Boerma (Eds.) (2005). Primary Care in the Driver's Seat? Organisational Reform in European Primary Care, London, Open University Press.

Scott, A., P. Sivey, D. Ait Ouakrim, L. Willenberg, L. Naccarella, J. Furler and D. Young (2011). 'The effect of financial incentives on the quality of health care provided by primary care physicians', Cochrane Database of Systematic Reviews, 9, 1-59.

Staines, A., K. Balanda, S. Barron, Y. Corcoran, L. Fahy, L. Gallagher, T. Greally, J. Kilroe, C. Mohan, A. Matthews, E. McGovern, A. Nicholson, A. O'Farrell, R. Philip and H. Whelton (2016). 'Child Health Care in Ireland', The Journal of Pediatrics, 177, S87-S106.

Steinbrook, R. (2009). 'The End of Fee-for-Service Medicine? Proposals for Payment Reform in Massachusetts', New England Journal of Medicine, 361, 1036-1038.

Struijs, J. and C. Baan (2011). 'Integrating Care through Bundled Payments - Lessons from the Netherlands', New England Journal of Medicine, 364, 990-991.

Tickle, M., R. McDonald, J. Franklin, V. Aggarwal, K. Milsom and D. Reeves (2011). 'Paying for the wrong kind of performance? Financial incentives and behaviour changes in National Health Service dentistry 1992-2009', Community Dentistry and Oral Epidemiology, 39, 465-473.

Tubert-Jeannin, S., C. Auclair, E. Amsallem, P. Tramini, L. Gerbaud, C. Ruffieux, A. Schulte, M. Koch, M. Rège-Walther and A. Ismail (2011). 'Fluoride supplements (tablets, drops, lozenges or chewing gums) for preventing dental caries in children', Cochrane Database of Systematic Reviews.

Voinea-Griffin, A., D. Rindal, J. Fellows, A. Barasch, G. Gilber and M. Safford (2010). 'Pay for performance in dentistry: what we know', Journal for healthcare quality: official publication of the National Association for Healthcare Quality, 32, 51-58.

Whelton, H., E. Crowley, D. O'Mullane, N. Woods, C. McGrath, V. Kelleher, H. Guiney and M. Byrtek (2007). 'Oral Health of Irish Adults 2000-2002', Final Report April 2007, Dublin, Department of Health. 
Whelton, H., D. O' Mullane, M. Harding, H. Guiney, M. Cronin, E. Flannery and V. Kelleher (2006). North South survey of children's oral health in Ireland 2002. Cork, Brunswick Press.

Wong, M., A. Glenny, B. Tsang, E. Lo, H. Worthington and V. Marinho (2010). 'Topical fluoride as a cause of dental fluorosis in children', Cochrane Database of Systematic Reviews.

Woods, N. and S. Ahern (2016). 'Capitation Systems in the Delivery of Oral Health Care. An International Overview', Unpublished report for the Department of Health Oral Health Policy Academic Reference Group.

Woods, N., J. Considine, S. Lucey, H. Whelton and T. Nyhan (2010). 'The influence of economic incentives on treatment patterns in a third-party funded dental service', Community Dental Health, 27, 18-22.

Wren, M., S. Connolly and N. Cunningham (2015). 'An Examination of the Potential Costs of Universal Health Insurance in Ireland', Research Series Number 45. Dublin, Economic and Social Research Institute.

Wren, M., C. Keegan, B. Walsh, A. Bergin, J. Eigan, A. Brick, S. Connolly, D. Watson and J. Banks (2017). Projections of Demand for Healthcare in Ireland, 2015-2030: First Report from the Hippocrates Model, Dublin, Economic and Social Research Institute. 
Whitaker Square,

Sir John Rogerson's Quay, Dublin 2

Telephone +35318632000

Email admin@esri.ie

Web www.esri.ie

Twitter @ESRIDublin

ISBN 978-0-7070-0471-6 